\title{
Cash and livelihoods in contexts of conflict and fragility: implications for social assistance programming
}

Jeremy Lind, Rachel Sabates-Wheeler and Carolina Szyp

BASIC Research

February 2022

Implemented by

institute of development studies OF SUSSEX

\section{CIDT}

Centre for International Development and Training 


\section{Summary}

This paper examines the role of cash-plus programming (including graduation) for livelihoods, income, protection, and health outcomes in contexts of different conflict intensity. We assess the origins of cash-plus programming (including graduation) for livelihoods outcomes as it has developed in settings that are more peaceful and where social protection systems are stronger. The paper then considers fragile and conflictaffected settings (FCAS), where social protection systems are often weak, and the threat of conflict-related violence undermines livelihoods as well as programming operations. We introduce a simple framework to understand programming contexts in FCAS, using both the strength of the social protection system as well as the intensity of conflict to identify four broad categories or landscapes for cash-plus programming. We use this framework to present the findings of a comprehensive review and analysis of 42 cash-plus programmes in 17 fragile and conflict-affected countries. This review maps key features in design and implementation of social and humanitarian cash assistance augmented by livelihood support across FCAS. There is significant variation, and few dominant patterns, in the objectives, coverage, duration, type of support, implementers, and impacts of programmes. This reflects the very different landscapes of conflict and systems of social assistance provisioning that exist across the countries covered in the review. Finally, we draw out lessons, questions, and challenges for programme design and implementation across different contexts and provide suggestions for future deeper research on these themes in the Better Assistance in Crises (BASIC) Research programme.

\section{About the authors*}

Dr Jeremy Lind is Research Fellow at the Institute of Development Studies (IDS) at the University of Sussex. He is a development geographer of the Horn of Africa, focusing on conflict, violence, and livelihoods, particularly in pastoralist areas. He has more than 20 years of academic research, advisory work, and project management experience, working with a range of government and non-governmental actors at the national and sub-national levels in the Horn of Africa as well as scholars and advocates in the region. He is Research Director for the Better Assistance in Crises (BASIC) Research programme.

Rachel Sabates-Wheeler is a Research Fellow at IDS and Co-Director of the Centre for Social Protection, with more than 25 years of experience working in rural development, poverty analysis, migration, and social protection. She has published widely and has worked for numerous international agencies. Since the mid2000s, Rachel has been at the centre of many large research programmes that explore understandings of risk and vulnerability, both conceptually and empirically. Currently, Rachel is Co-Executive Director of the BASIC Research programme.

Carolina Szyp is a Research Officer at IDS. Her research experience and interests include youth livelihoods, decent work, education, and social protection. Since joining IDS, she has worked on a number of projects looking at how young people engage with the rural economy and focusing on the impact of social protection interventions on youth employment outcomes.

* The authors made equivalent contributions. 


\section{Contents}

1. Introduction $\quad 4$

2. Social assistance and livelihood programming in stable contexts 4

3. Livelihoods, vulnerability, and social assistance in fragile and conflict-affected settings 9

4. Methods $\quad 11$

4.1 Description of programme data 12

4.2 Country categorisation $\quad 12$

$\begin{array}{lr}\text { 5. Findings and analysis } & 14\end{array}$

$\begin{array}{ll}5.1 \text { Objectives } & 14\end{array}$

5.1.1 Relief (or protective social protection) 14

5.1.2 Recovery (a mixture of protective and promotive social protection) 15

5.1.3 Resilience (a mixture of preventive and promotive social protection) 15

5.1.4 Promotion (or promotive social protection) 15

5.1.5 Peacebuilding (or transformative social protection) 15

5.1.6 Analysis of programming objectives in different implementation settings 16

$\begin{array}{ll}5.2 \text { Modalities } & 17\end{array}$

$\begin{array}{ll}\text { 5.2.1 Cash component } & 17\end{array}$

$\begin{array}{ll}5.2 .2 \text { 'Plus' component } & 17\end{array}$

5.2.3 Analysis of programming modalities in different implementation settings 18

$\begin{array}{ll}5.3 \text { Targeting criteria } & 19\end{array}$

5.4 Implementers $\quad 21$

5.5 Impacts and outcomes $\quad 21$

6. Discussion $\quad 22$

$\begin{array}{ll}\text { 7. Research agenda } & 24\end{array}$

$\begin{array}{lr}\text { References } & 25\end{array}$

$\begin{array}{lr}\text { Annexes } & 27\end{array}$

$\begin{array}{ll}\text { Annexe 1: Methods } & 27\end{array}$ 


\section{Introduction}

Innovations in social protection programming in recent years have taken the form of a variety of 'graduation' and cash-plus interventions, all aiming to support lives (to protect against and prevent deprivation) and livelihoods (to become more productive and sustainable). Most of these programmes are implemented, and often scaled up, in contexts of relative stability, where state systems for their design and delivery mostly exist and function, even if with some support from international actors. Increasingly, these programmes are also piloted and implemented in settings affected by conflict and exhibiting various features of 'fragility'. ${ }^{1}$ These are initiated either exclusively by international actors under the banner of humanitarian cash and livelihood support, or as graduation or cash-plus programmes that seek to embed themselves in future or nascent state social protection systems. Whether these programmes are appropriate for conflict-affected settings is uncertain, as there is limited literature analysing the nature, form, and outcomes of these interventions in such contexts, as we discuss below.

This paper considers the implications of conflict and violence for the sustainable livelihoods aspirations inherent in graduation and/or other types of cash-plus programming. We start by explaining the origins and emergence of graduation and cash-plus programmes - primarily developed in stable contexts. The paper then considers the unique features of fragile and conflict-affected contexts in relation to social protection and livelihood programming. We then provide a comprehensive review and analysis of cash-plus programmes in 17 fragile and conflict-affected settings (FCAS). The review maps the key features in the design and implementation of cash-plus assistance (which, for the purposes of this paper, means cash transfers augmented by livelihood support) across fragile settings differentiated by the intensity of conflict they experience as well as the maturity of social protection systems that are present. The purpose is to determine whether there are clear differences in the method of provision and type of complementary support provided across the different contexts and to reflect on whether these cash-plus programmes are fit for conflictaffected settings. The final section draws out lessons, questions, and challenges for programme design and implementation across different contexts. We also provide suggestions for future deeper research on these themes in the BASIC Research programme.

\section{Social assistance and livelihood programming in stable contexts}

The confluence of social assistance and livelihood programming has become a mainstay in the field of social protection over the past $10-15$ years. ${ }^{2}$ In the early days of social protection, interventions and instruments were limited primarily to regular food and cash transfers (sometimes also asset transfers) with the purpose of protecting lives through consumption and food security support, and contributory insurance mechanisms such as pensions and unemployment benefits, with the aim of preventing damaging downturns in economic wellbeing over the life cycle. Popularised through the work of Devereux and Sabates-Wheeler (2004), the terms used to describe these functions of social protection include 'protective' (providing relief from poverty and deprivation through the provision of welfare and social services) and 'preventive' (seeking to prevent deprivation through formal and non-formal insurance strategies).

In fact, smoothing consumption and income remains the core contribution of social protection support. Yet, claims have always been made about the potential of well-designed and delivered social protection programmes to achieve second-tier outcomes - outcomes that go well beyond supporting lives to promoting and enabling resilient and strengthened livelihoods (Sabates-Wheeler 2021). This function of social

\footnotetext{
${ }^{1}$ Definitions of state fragility tend to emphasise situations where state institutions are weak or contested, and where governance and political legitimacy is poor. For example, OECD (2020) characterises fragility as the combination of exposure to risk and insufficient coping capacity of the state, systems and/or communities to manage, absorb or mitigate those risks.

2 We use the terminology 'social assistance' as opposed to the broader agenda of social protection because, for the purpose of this paper, we are primarily interested in one instrument - that of cash transfers, which are a classic social assistance instrument - and how this instrument is combined with 'plus' components. Social assistance is a core function/instrument within a larger social protection terrain.
} 
protection is couched as 'promotive' and refers to measures to enhance real incomes and capabilities. Yet there is debate about how this occurs. Early proponents of social transfers argued that regular and predictable payments of cash or food alone would function both as a safety net for consumption and income but also as a risk insurance mechanism for future downturns and would enable recipients to take small entrepreneurial risks in the current period. The regularity and predictability were the incentives needed to encourage small investments in livestock, business, health, or education that would have productive payoffs that could be cumulative and therefore lead to more productive and resilient livelihoods. (A fourth function of social protection is 'transformative' - that is, seeking to address exclusion and equity in access and provision (ibid.). Yet attention to this aspect within policy and programming remains limited.)

However, while abundant evidence points to the consumption and food security benefits of regular social assistance (Baird et al. 2013; Davis et al. 2016; Bastagli et al. 2016; Hidrobo et al. 2018; Millán et al. 2019), recent evidence indicates that the promotive impacts of regular cash and food transfers are limited (Attah et al. 2016; Millán et al. 2019). In other words, there has been a realisation that cash transfers alone would not provide a silver bullet (Adato and Hoddinott 2007) to transform livelihoods into something 'sustainable'. Academic work on asset thresholds supported this view that low and regular payments of cash might be beneficial for survival, but unless much more substantial payments are provided that move people over critical thresholds, the households are likely to remain trapped in poverty (Carter and Barrett 2006; Carter and May 2001).

Influenced by this and other evidence from a range of small-scale pilots in Africa (Ellis, Devereux and White 2009) as well as other social assistance programming led by non-governmental organisations (NGOs) in Asia (BRAC in Bangladesh) and work on enablers/constrainers of graduation (Sabates-Wheeler and Devereux 2013), attention shifted towards the additional support required to augment cash or food transfers that would allow households not just to survive but to thrive (see Sabates-Wheeler et al. 2021 for a review). Emerging from this came a slew of programmes that are known as graduation programmes. Similar in composition to any integrated livelihood programme, what distinguishes these is the centrality of regular provision of social assistance (usually in the form of cash but could also be food or assets) to the package of support. Fundamentally, then, the theory is that cash - augmented with other forms of support as a way of strengthening productive livelihoods - will, over time, contribute to creating 'productive' (promotive) and/or 'sustainable' livelihoods for beneficiaries, even in the absence of social assistance when it is withdrawn.

'Sustainable graduation' refers to a state in which livelihoods have been fundamentally transformed through a comprehensive package of interventions that have social protection instruments at the core (SabatesWheeler and Devereux 2013). This is substantively different from meeting a specified benchmark, as it is about supporting a positive change in livelihoods over time. The most well-known graduation model was developed and implemented by BRAC for its Challenging the Frontiers of Poverty Reduction - Targeting the Ultra Poor (CFPR/TUP) programme in Bangladesh in 2002 (Hashemi and Umaira 2011). Their graduation approach was later adopted by the Consultative Group to Assist the Poor (a global partnership of 34 organisations) and was piloted in several other countries. This specific version of the model combines cash transfers with asset support, savings, microfinance, and training.

Other graduation programmes combine cash, food, and/or asset transfers with additional service components (e.g., credit, training, sensitisation meetings, psychosocial support) or with linkages to social services. These transfers could be conditional or unconditional. Well-known programmes, such as the Vision 2020 Umurenge Programme (VUP) in Rwanda and the Productive Safety Net Programme (PSNP) in Ethiopia, share these similar elements. For instance, the VUP provides cash payments to the poorest households; those households with labour are required to perform public works (also known as cash-forwork), while those that are labour-constrained are given cash with no conditions. Public works beneficiaries are also able to access extension services, credit, and support to promote small business development. In addition to state-supported programmes, there are also a plethora of NGO-funded and supported small-scale graduation pilot or graduation-like bundled services programmes that combine different elements to meet the various needs of distinct target populations. Due to short funding cycles, these NGO programmes typically 'require' that graduation takes place within a two- or three-year time frame. 
For this paper, we use the terminology of graduation and cash-plus, with a preference for cash-plus recognising that there are many programmes providing a bundle of services that might not hit all the marks of a 'graduation' programme. The difference in language reflects an evolution in the preference of policy and programming terminology. Graduation programmes tend to be more comprehensive in terms of providing a package of support to a population group for a specific purpose with a more specific timeline or progression to the package, such as cash plus extension services, financial literacy, public works, and credit within one programme for the purpose of addressing poverty and encouraging better farming or business practices. Cash-plus can be anything from cash and training on nutrition or cash augmented with multiple other interventions. Cash-plus programmes frequently link people to a broad range of social services (including social workers or psychosocial support) with the purpose of improving a range of human development outcomes, including poverty (Roelen et al. 2017; Watson and Palermo 2016). Technically speaking, a graduation programme is a cash-plus programme - just a more comprehensive package of complementary components in sequence with a specific timeline, and often focused on economic outcomes. Cash-plus includes components as well as linkages, both in relation to economic and social outcomes.

Broadly speaking, all graduation programmes have two levels of outcomes that are sequentially achieved if the programme is to be deemed a success. The first level relates to food security and basic needs provision - typically measured in terms of consumption or other poverty indicators. Once this has been achieved, then the second-level outcome becomes improvement in livelihoods, health, and opportunities for the household (for specific cash-plus programmes). The second level requires that beneficiaries can productively use the complementary package of support available to them (such as credit, assets, training, education, nutrition, etc.) or make use of linkages to complementary services (nutrition, health, education) to improve their wellbeing or livelihood opportunities. This is typically evidenced through higher investments (income, assets, and human capital), better human development outcomes, asset accumulation, and savings.

Development of, and lessons from, graduation and cash-plus programming come almost exclusively from contexts that are stable, but which exhibit high levels of chronic poverty. In other words, in contexts where institutions exist and can deliver regular payments, where coordination across provision of a package of support is in place, and where there is limited armed conflict or potential for such. These systems and interventions might be funded, delivered, and coordinated by governments or by a combination of development donors, government, and NGO support - for instance, as in Ethiopia's PSNP or the Livelihood Empowerment Against Poverty (LEAP) programme in Ghana. Yet, even within contexts of stability where programme implementation is relatively straightforward, research findings show that there are a range of institutional and structural constraints to achieving proposed outcomes (Sabates-Wheeler and Devereux 2013; Sabates-Wheeler et al. 2020). Cash-plus provision is primarily tailored for and targeted at households and individuals, with little attention paid to the broader economic and political context within which people live and work. Whether programmes are successful or not, and whether they are even an option, depends on the wider environment - for example, is infrastructure available, are markets accessible, and do government structures function? And these questions arise from just analysing stable contexts. What, then, of more fragile and uncertain contexts where conflict or the threat of conflict is ever present?

Work from the Social Protection Inter-Agency Cooperation Board (SPIAC-B) as well as Winder Rossi et al. (2017) usefully distinguishes different social protection scenarios in relation to state (national government) involvement in social protection provision and country context (see Table 2.1). The scenarios range from complete absence of social protection provision due to conflict or war, to a situation in which the social protection system is flexible (or fully shock-responsive) and able to respond in an appropriate and efficient manner after a shock. Category 1 (no system) and category 5 (highly shock-responsive system) should be considered as 'reference scenarios'. The three intermediate categories range from a situation in which a coherent social protection system is not yet developed to one in which a national social protection system exists but is only partially able to adapt and respond to shocks.

These scenarios help to illustrate the different providers, types of interventions, and methods of delivery that are most appropriate in the different contexts. For instance, where a system is shattered or severely weakened, the most appropriate provider of cash assistance is most likely the international humanitarian system. Where the state system exists but is weak, the international system can provide support to strengthen state-led social protection and deliver humanitarian resources through the system. Ideally, in a stable context, social assistance is provided through the state social protection system. Most of the scaled 
graduation and cash-plus programmes are implemented in contexts that correspond to categories 4 and 5 . In other words, these are the contexts in which the promotive function of social protection is most likely to bear results. In contexts such as categories 1 and 2 , the protective and preventive functions take precedent as relief against destitution and deprivation. Other functions specific to FCAS, such as recovery and peacebuilding, also come into play in scenarios 1, 2 and 3. Supporting sustainable livelihoods will also be possible in category 3 , if supported by non-state actors and combined with recovery and peace-building initiatives.

\section{Table 2.1: Maturity of social protection system}

\begin{tabular}{|l|l|l|}
\hline N. & $\begin{array}{l}\text { Type of social protection } \\
\text { context* }\end{array}$ & Description \\
\hline 1 & $\begin{array}{l}\text { Shattered or severely } \\
\text { weakened system }\end{array}$ & $\begin{array}{l}\text { Context where there is no formal provision of social protection and/or existing } \\
\text { structures (formal and non-formal) have been shattered or severely weakened } \\
\text { by crises or conflict. }\end{array}$ \\
\hline 2 & $\begin{array}{l}\text { Nascent social assistance } \\
\text { system }\end{array}$ & $\begin{array}{l}\text { Initial components of a social protection system are being put in place, providing } \\
\text { short- to medium-term support mostly in relation to acute risks, threats, or } \\
\text { crises. Yet a coherent system is not developed. }\end{array}$ \\
\hline $\mathbf{3}$ & $\begin{array}{l}\text { State social protection } \\
\text { system unable to respond } \\
\text { to repeated crises }\end{array}$ & $\begin{array}{l}\text { A social protection programme or system exists and is institutionalised within } \\
\text { the state structure, yet it is rigid and inflexible or too overloaded; it is unable to } \\
\text { adapt to increasing burden of need in the event of a shock or crisis. }\end{array}$ \\
\hline 4 & $\begin{array}{l}\text { Limited shock-responsive } \\
\text { national social protection } \\
\text { system }\end{array}$ & $\begin{array}{l}\text { A social protection programme or system exists that includes committed state } \\
\text { involvement (even if it is donor-funded). The system is partially able to respond } \\
\text { to predictable shocks and increase coverage of those households affected by } \\
\text { the shock and eligible to receive social protection. }\end{array}$ \\
\hline $\mathbf{5}$ & $\begin{array}{l}\text { Highly shock-responsive } \\
\text { national social protection } \\
\text { system }\end{array}$ & $\begin{array}{l}\text { An ideal scenario where a social protection system is institutionalised within } \\
\text { state structures and is prepared to respond nimbly and flexibly to predictable } \\
\text { and unpredictable shocks and stresses. }\end{array}$ \\
\hline
\end{tabular}

Source: Winder Rossi et al. (2017)

*These reference-only categories were developed based on the Core Diagnostic Instrument (CODI). CODI is one of the tools developed as part of the SPIAC-B set of diagnostic inter-agency tools. http://ispatools.org/core-diagnostic-instrument/

If cash-plus programmes are designed primarily to help chronically food-insecure households to engage with a rural economy that is otherwise performing and where productive livelihoods are possible, what is the prognosis of these programmes where markets are disrupted, infrastructure is destroyed, and the notion of 'sustainable' livelihood is questionable? The recent eruption of conflict in the Tigray region of Ethiopia provides vital insights into the likely effects of conflict on graduation programmes for livelihood promotion (see Box 2.1).

We are interested here in what happens to graduation and cash-plus programmes in contexts where the social protection system is weakened by a conflict, or where provision is fragmented and some aspects of the social protection delivery system (targeting, funding, coordination, appeals) are non-existent. How do cashplus livelihood programmes perform when they are implemented in FCAS where institutional capacity is weak, markets are not dynamic (if they exist at all), uncertainty and the threat of conflict prevails, and poverty is acute? Existing graduation programmes are almost exclusively happening in relatively peaceful settings; they do not generally take place in situations of armed conflict. Cash-plus programmes are used in some conflict-affected places - but the key point is that the persistence of conflict means that 'graduation' is often not an option. So, the question remains: how to strengthen livelihoods in FCAS, particularly when conflict dynamics involve types of violence and armed activity that seek to destroy livelihoods. 


\section{Box 2.1: Conflict and the limits of social assistance and livelihoods programming in Tigray,}

Ethiopia

The current humanitarian crisis in Ethiopia's Tigray region demonstrates the sensitivity of even the most welldeveloped social protection systems to conflict shocks. Before the conflict began in Tigray in November 2020 , the region was one of the best-performing in the country's graduation programme - the Productive Safety Net Programme (PSNP) (Sabates-Wheeler et al. 2020). An estimated 1 million Tigrayans received monthly food or cash transfers, partly using an electronic payment system. PSNP public works represented a sustained investment in climate resilience in the drought-prone region. Complementary programme efforts focused on strengthening livelihoods through extension services, business and technical skills training, workforce development, and linkages to employment. All of this was highly coordinated and directed by the state at multiple levels of political administration, from the federal right down to the sub-district level.

Designed to address food security concerns in response to seasonal droughts, the PSNP (like most social protection programmes) was not set up to be responsive to a severe and unanticipated conflict shock. Instead, the expectation is that humanitarian assistance will fill the void left by the retreat (and possibly collapse) of pre-existing systems of social assistance to meet the deeper and wider needs of a conflictaffected population. Yet, since the conflict in Tigray began, a grave humanitarian crisis has erupted alongside the degradation and disruption of response capacities, with restrictions on humanitarian access in large areas of the region. In many areas, woreda (district) and tabiya (sub-district) personnel who were on the front line of PSNP delivery were themselves displaced during the conflict. Outside of the regional capital, Mekelle, many government employees did not receive their salaries for months. Shops that had been used to provide cash payments to some PSNP beneficiaries were shuttered and many looted (Anna 2021), as were banks. Even if an infrastructure for cash responses were still functioning, markets did not operate in most areas, with insecurity rampant as well as destroyed roads and bridges impeding access.

While agencies and governments around the world aim to fuse shock-responsive elements onto social protection programmes, the curtailment of the PSNP in Tigray stands as a cautionary tale. The impacts of acute conflict are important to understand because they point to vulnerabilities in systems of provisioning and provide insights into how the PSNP may be made more resilient in the face of future conflict. The continuity of benefits (a gold standard for social protection) is broken as payment systems are derailed. The provision of services collapses when ground-level implementers, such as agriculture extension and public health workers, are themselves displaced. Accessibility to operational areas - for assessment, delivering supplies and food, and monitoring - is obstructed by damage to roads and communications as well as the continuing threat of attacks on responders (including food aid transporters). These impacts signify the difficulties of ensuring the continuation of basic programme operations, let alone the smooth running of a mix of inputs and services in parallel that is necessary to operationalise graduation approaches. 


\section{Livelihoods, vulnerability, and social assistance in fragile and conflict-affected settings}

In situations of fragility and conflict, supporting livelihoods - whether through social protection or other measures - is very difficult and far from certain. Conditions of a 'slow-burning crisis' last many years, there are multiple stressors and pressures on people's productive activities, mechanisms for intervention are constrained, there is a disproportionate dependence on humanitarian agencies to jumpstart 'development', and the capacity of local government to deliver development - both social and economic services as well as supporting stable governance - is weakened (Maxwell, Russo and Alinovi 2012). Especially at the rural margins, in places that are excluded or otherwise neglected by central governments, markets, livelihoods and services are largely informal and sometimes illegal (Ahmad 2015; Cheng 2016). Still, regardless of the relative weakness of state institutions in FCAS (including those underpinning the social protection system), parallel institutions and hybrid arrangements often exist through which people access livelihoods, basic services, and social assistance. These arrangements have differentiated impacts on the wellbeing of individuals, households, and communities, imposing costs (both economic and physical) as well as providing benefits (Justino 2018).

We still know very little about how vulnerable groups - largely bypassed by official actors - endure the hardship of fragility and conflict; how they mobilise collective action to govern access to basic services and social assistance, and use (scarce) political, social, and economic resources, including those at the margin of the rule of law, to make a living and survive. They often face direct and structural violence on a daily basis, while also lacking the quality and substance of citizenship. The general tendency of research on conflict has been to view affected populations as mostly victims, with limited attention to the role played by their choices and preferences, including the type and effectiveness of adaptation strategies they employ to protect lives and livelihoods. They navigate their insecurity and access to livelihoods, services, and assistance in ways that find little or no reflection in the dominant state security narratives, or indeed in more universal conceptions of an operational 'social contract' (Bates 1983; Olson 1993). These dynamics pose considerable challenges for 'formal', programmed types of social assistance that target and seek to uplift the livelihoods of vulnerable populations. While not discounting the existence of people who are in desperate need, fragile and conflict-affected populations are not waiting to be 'assisted', much less 'graduated'; rather, they are seeking access to services and assistance in ways that continuously evolve, and often through channels that are invisible (and, hence, unnoticed), dictated by identity and personal connections (rather than objective programme criteria) and, in some cases, through public authorities that are designated as 'terrorists', rebels and other non-state armed groups.

The defining feature of most fragile contexts is a background and continuation of conflict and violence. Continuing insecurity, set against the legacies of conflict - including large population displacements, upturned rural social structures, rapid urbanisation, resource depletion in peri-urban environments, the emergence of new violent institutions, and more rigid relations between different identity groups - presents very real difficulties in improving the situations of displaced populations and others assisted in these situations. Conflict reshapes access to resources and markets as the basis of resilient lives. The impacts on agricultural and pastoral livelihoods are particularly severe through depleted assets, diminished or no access to land and resources, the loss of agro-ecological knowledge among a younger generation, feelings of mistrust between different groups, militarisation, and armed self-defence. There is now far greater fluidity in livelihoods systems than previously (borne out of necessity, in part) and a stronger emphasis on urban settlement as a basis for livelihood activities (borne out of persistent insecurity in rural areas). Previous livelihood categories of farmers, herders, traders, and mixed livelihoods systems are far harder to adhere to and potentially dangerously misleading. Multiple livelihood situations can be juxtaposed in the same place, reflecting the diverse backgrounds of different actors and groups, their opportunities, and options to improve their situation, and their own goals and aspirations.

These dynamics have clear and present implications for social assistance efforts. Promoting livelihoods that are 'sustainable' - so often the focus of programming in settings without armed conflict - is a shifting and misleading guidepost for social assistance programmes that seek to improve livelihoods in areas where 
conflict and violence continue. Rather, protection is at the core of most efforts to provide social assistance in relation to shorter-term relief as well as longer-term processes of recovery and rehabilitation. Rehabilitation focuses on restoring access to basic services and to household livelihoods, and to state and enterprise as well as to the social, community, and local infrastructure necessary to attain those ends (Green 2000: 343). Rehabilitation assistance may entail efforts to 'promote' livelihoods. Yet often what is meant by 'livelihood promotion' is more akin to livelihood 'creation': providing particular conflict-affected groups with access to a means of livelihood (often a portfolio of multiple livelihood activities) in situations where pre-conflict livelihoods are no longer possible. Examples include training in new activities like brickmaking for residents in camps for internally displaced persons (IDPs) in South Sudan who used to practice agro-pastoralism or equipping young men in Darfuri camps with donkey carts as a way to generate income for themselves in local haulage and transport (Maxwell, Gelsdorf and Santschi 2012; Young et al. 2009; Young and Jacobsen 2013).

The nature, range, and pattern of conflict and violence greatly affect livelihood strategies in protracted crises, both as a source of shock as well as in relation to processes of recovery and rebuilding. Conflict contexts range from high-intensity conflicts such as in Syria and Yemen, to long-term moderate conflicts marked by episodic periods of higher levels of violence such as in Darfur, Mali, and Somalia, to areas with protracted but lower-intensity conflicts such as in Colombia, Haiti, and Pakistan. Other areas, such as Lebanon, Jordan, Uganda, and Kenya, do not experience widespread armed conflict but host large conflict-displaced refugee populations from neighbouring countries. These categories conceal considerable variation in conflict and the far greater complexity and nuance that characterises particular conflicts. For example, in West Africa, there has been a widespread escalation of conflict between herders and farmers, particularly in Nigeria, with thousands reported dead, and stark politicisation of ethnic tensions (Amnesty International 2018). In Mali, civil conflict in the north of the country is pitting certain pastoral groups against the central government, while in the centre of the country, jihadist forces have successfully mobilised some Fulani peoples who have suffered decades of neglect and loss of grazing land (Benjaminsen and Ba 2019).

\section{Figure 3.1: Fragility and maturity of social protection system}

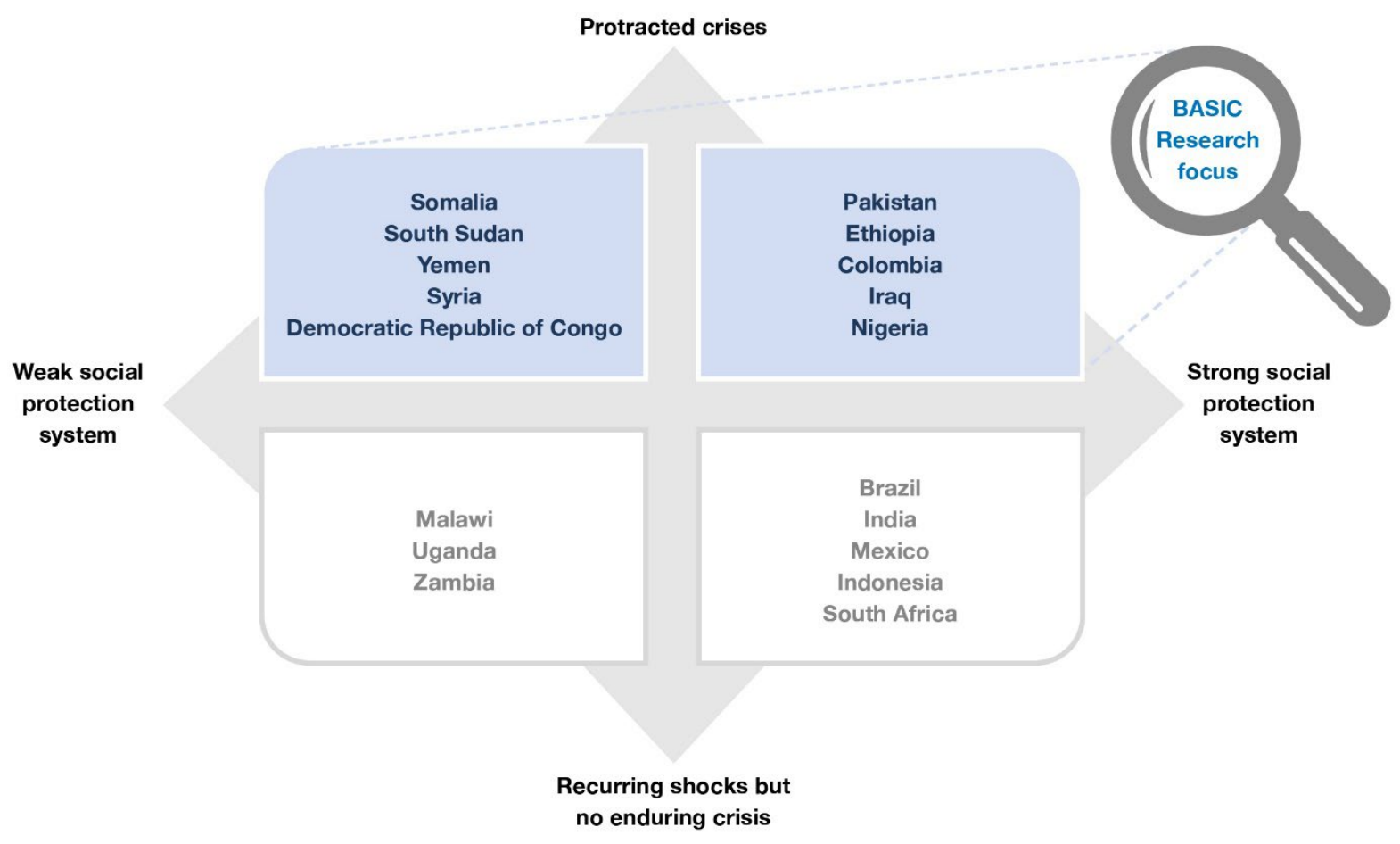

Source: Authors' own.

The intensity of conflict can be considered alongside the strength of state-led social protection systems, as described in the previous section, to develop broad categories describing contexts for cash-plus programming that seeks to strengthen livelihoods (Figure 3.1). In settings that are 'peaceful' (that experience no armed conflict-related fatalities), but that have existing social protection programmes and systems (the 
bottom-right quadrant), such as in many areas of Brazil, India, Mexico, Indonesia, South Africa, and the Philippines, the assumption would be that it is possible to provide the full range of services and support in parallel with supporting improvements in livelihoods along a pathway to graduation. In settings that are peaceful or experience minimal levels of conflict-related violence and have weak social protection systems and programmes (the bottom-left quadrant), such as in Malawi, Zambia, and southern Uganda, where security conditions do not restrict cash-plus programming, delivery may be constrained by the lack of coordination and direction by state policy and decision-making, and therefore a proliferation of small-scale programmes by NGOs and other aid actors may be evident. In the top two quadrants of Figure 3.1 (which are the focus of BASIC Research), conflict-related violence on a scale of increasing intensity (as described above) shapes both the setting in which people make a living - and thus compromises any pursuit of building a livelihood that is 'sustainable' - and defines the space for programming and operations. Some contexts such as Pakistan, Ethiopia, Colombia, Iraq, and Nigeria have elements of social protection systems and programmes, but these may function poorly, if at all, in sub-national pockets and areas that experience more intense conflict, and/or during periods when levels of conflict are acutely high. In these areas, even though there may be structures in place to deliver cash-plus programmes, these are often not sustainable when there are high levels of conflict. The challenges for cash-plus programming are greatest in the top-left quadrant, which are contexts that are conflict-affected and have weak, non-existent, or shattered social protection systems and programmes, such as in Syria, Yemen, the Democratic Republic of Congo (DRC), and South Sudan.

In recent years, multiple efforts have been made to introduce graduation and cash-plus programmes into FCAS, but little learning has been generated about the conditions under which these programmes might be beneficial and how a context characterised by conflict-related violence or specific populations affected by crisis (such as refugees) might influence the most appropriate package of support. Much of the evidence base comprises case studies of specific countries/programmes, or grey literature such as guides from specific organisations, but there has been little more comprehensive analysis. In the next section, we focus on the top two quadrants of Figure 3.1 - that is, countries and contexts experiencing conflict-related violence or hosting conflict-displaced populations. We map levels (intensities) of conflict and the strength of the stateled social protection system for each country. This allows us to develop four conflict-social protection context categories. Across these, we assess the features of cash-plus programming in 18 FCAS, as well as evidence of their outcomes, drawing on a comprehensive review exercise (as explained below).

\section{Methods}

This review draws on grey and academic literature focused on social and humanitarian cash assistance augmented by livelihood support (cash-plus, for short) in FCAS by formal state and non-state actors (national and international). Documents reviewed include academic journal articles, grey literature, books and book chapters, and $\mathrm{PhD}$ dissertations. Additional inclusion criteria are: only documents for programmes active at some point during the past ten years (since 2011); and those published in English and that cover any of the BASIC Research countries. ${ }^{3}$ While a very wide range of programmes and projects implemented in FCAS are classified as 'livelihood' programmes - from training in agricultural and veterinary techniques to small- and medium-enterprise (SME) development, and microcredit - for the purpose of this review we are interested only in those programmes that combine cash transfers (social assistance) with other programming elements that are intended to support livelihoods. (For a detailed review of the full range of livelihood programmes in fragile contexts, see Wiggins et al. 2021.) Specifically, we identify programmes that include a social assistance component (transfer of cash, conditional or unconditional, including public works programmes and grants) accompanied by complementary, livelihood-focused interventions such as skills training, asset transfers, agricultural extension, microcredit, access to finance, and animal health services. For more details on the methodology, see Annexe 1.

3 These include Yemen, Somalia, Lebanon, Jordan, Niger, Mali, Nigeria, Iraq, DRC, Congo, South Sudan, Ethiopia, Mozambique, Central African Republic, Libya, Syria, Afghanistan, Myanmar, Pakistan, Haiti, Colombia, Venezuela, and Ukraine. These countries are the focus of the BASIC Research programme and were selected as contexts where there are overlapping challenges from conflict, climate change, extreme and chronic poverty, humanitarian crisis, and fragility. 
As the core objective of this paper is to understand how cash-plus programmes are implemented across different FCAS, and how that might be different from settings not characterised by protracted conflict and displacement, we focused on particular programme design and implementation aspects (such as programme objectives, modalities, targeting criteria, etc.) as well as the methods that evaluation reports have used for these programmes (quantitative survey work, qualitative, mixed methods).

\subsection{Description of programme data}

A total of 42 programmes met the criteria for our review, implemented in Nigeria, Yemen, Somalia, South Sudan, Lebanon, Pakistan, Afghanistan, Colombia, Haiti, Iraq, Jordan, Mali, Niger, DRC, Ethiopia, Mozambique, and Syria. Nigeria (north-east) had the largest number of programmes (six), whereas most of the other countries reviewed had one or two. The body of literature reviewed mostly included programme documents generated by the funding agencies, which encompass a description of project components, grey literature (e.g., policy briefs, etc.), and evaluation documents (including some journal articles; for more details, see 'impacts and outcomes' section on page 22). Just over half (22) of the programmes are small scale and include pilots or experimental programmes with limited coverage (less than 50,000 people or 10,000 households). Just over 10 per cent (five programmes) have a coverage of more than 250,000 people or 50,000 households. In almost all cases, the reach of programmes is limited to a particular sub-national context (a region/province or district(s) below this). On average, programmes lasted 4.8 years (median of 4 years). Three-quarters of the programmes include a conditional cash transfer (CCT) element, and only half have an unconditional cash transfer (UCT) component. Ten programmes include a mixture of CCTs (on work, business proposals, training) and UCTs (including grants). All programmes incorporate one or more other modalities beyond the cash transfer, mandatory or optional, including skills training (36 programmes), agricultural extension (15 programmes), access to finance (including microcredit) (13 programmes), and asset transfers (11 programmes). Additional components that were not in the inclusion criteria but that feature in the programmes are coaching, mentoring, and sensitisation (16 programmes), and market links and information (8 programmes). A number of other modalities were observed but were less common (featuring in less than five programmes each), including: animal health services; health care and counselling; apprenticeships and education; food assistance and nutritional supplements; and job matching.

\subsection{Country categorisation}

In this section, we present a categorisation of cash-plus in implementation settings defined by levels (intensities) of conflict and the strength of the social protection system. We used data from the Armed Conflict Location and Event Database (ACLED) ${ }^{4}$ to determine the 'level of conflict' in each of the countries, based on fatalities documented over the past three years (7 May 2018-7 May 2021). The ACLED data includes documented fatalities associated with the following types of violent events: riots; violence against civilians; battles; and explosions/remote violence. The conflict intensity scale in our model is derived from the definition of war used by the Uppsala Conflict Data Programme (UCDP) ${ }^{5}$ as well as the conflict intensity categories proposed by Gersovitz and Kriger (2013). Combining these, we developed four categories: no armed conflict; low intensity conflict; moderate conflict; and high intensity conflict (Table 4.1).

In our model, the scale of 'strength of the social protection system' is based on the corresponding categories provided by Winder Rossi et al. (2017) as described earlier in this paper (see Table 2.1). A common method or approach for measuring the robustness or maturity of social protection systems has yet to be developed; therefore, the placement of countries on the scale is determined through a combination of our expert knowledge, country review documents, and interviews and discussions with key stakeholders who work on social protection in these countries.

${ }^{4}$ https://acleddata.com/data-export-tool/ For this paper we looked at the option of using OECD data instead, which is based on a fragility index (wider than the violent conflict focus from ACLED), but it does not include data for Lebanon, Jordan, or Colombia. Also, data provided online is for the past year only (shorter period than ACLED). We are keen to triangulate ACLED and OECD data in future BASIC Research.

${ }^{5}$ UCDP defines war as: 'A state-based conflict or dyad which reaches at least 1000 battle-related deaths in a specific calendar year', https://www.pcr.uu.se/research/ucdp/definitions/. 
Table 4.1: Categories of conflict intensity

\begin{tabular}{|l|l|l|l|}
\hline Definition & Fatalities per year & Conflict level & Fatalities per year \\
\hline \multirow{2}{*}{ Minor } & $0-999$ & No armed conflict & $0-99$ \\
\cline { 3 - 4 } & & Low-intensity conflict & $100-999$ \\
\hline \multirow{2}{*}{ War } & $1,000+$ & Moderate conflict & $1,000-2,999$ \\
\cline { 3 - 4 } & & High-intensity conflict & $3,000+$ \\
\hline
\end{tabular}

Source: UCDP; Gersovitz and Kriger (2013).

Combining these scales, we develop four categories that define the implementation environment for cashplus and graduation programming in FCAS, adding further nuance to Figure 3.1 (see Figure 4.1):

- Low conflict, moderate social protection system strength $\left(\mathrm{C}_{\mathrm{L}} \mathrm{S}_{\mathrm{M}}\right)$ : countries experiencing an intensity of conflict at level three or below and whose strength of social protection system is three or above. This category covers Jordan and Colombia.

- Low conflict, low social protection system strength $\left(\mathrm{C}_{\mathrm{L}} \mathrm{S}_{\mathrm{L}}\right)$ : countries experiencing an intensity of conflict at level three or below and whose strength of social protection system is two or below. We include Lebanon, Haiti, Niger, and Mozambique in this category.

- High conflict, moderate social protection system strength $\left(\mathrm{C}_{\mathrm{H}} \mathrm{S}_{\mathrm{M}}\right)$ : countries experiencing an intensity of conflict at level four or above and whose strength of social protection system is three or above. We include Pakistan, Ethiopia, Iraq, Nigeria, and Syria in this category.

- High conflict, low social protection system strength $\left(\mathrm{C}_{\mathrm{H}} \mathrm{S}_{\mathrm{L}}\right)$ : this included countries experiencing an intensity of conflict at level four or above and whose strength of social protection system is two or below. We include Mali, South Sudan, Somalia, DRC, Yemen, and Afghanistan in this category.

Figure 4.1: Implementation contexts for cash-plus programming in conflict-affected situations

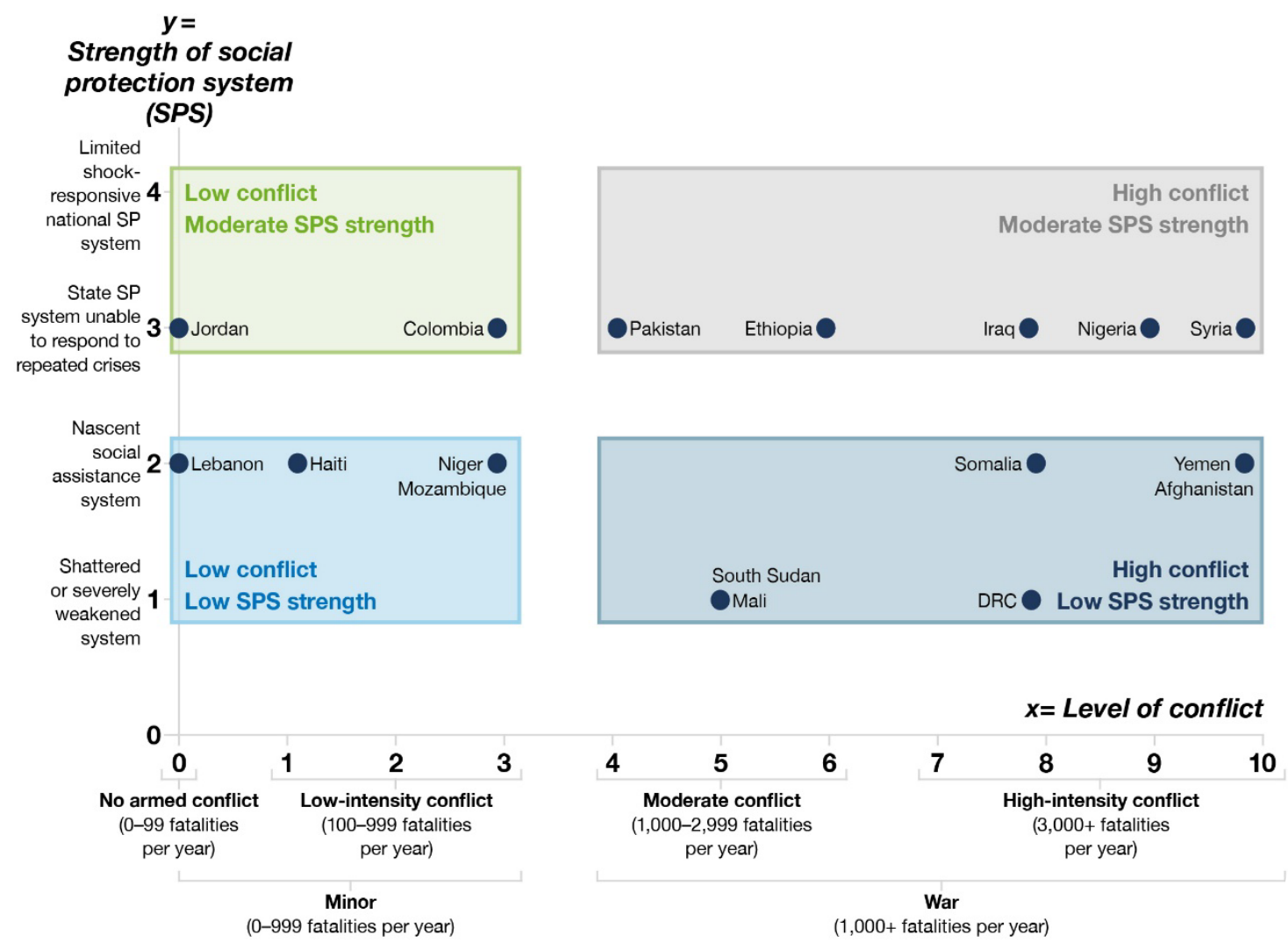

Source: Authors' own. 


\section{Findings and analysis}

\subsection{Objectives}

The objectives of the identified programmes can be classified as follows: livelihood relief, recovery, resilience, promotion, and peacebuilding. This language reflects the fact that these programmes are implemented in conflict-affected settings and often in contexts where humanitarian agencies and other non-state actors substitute for weakly developed or non-existent social protection systems. Table 5.1 compares the objectives of these programmes with those categories common in social protection programming (protective, preventive, promotive, and transformative ${ }^{6}$ ) as well as the distribution of these objectives across the four implementation settings as per Figure 4.1.

Table 5.1: Objectives of cash-plus programmes in conflict-affected settings*

\begin{tabular}{|c|c|c|c|c|c|c|}
\hline Objectives & Translation to SP & $\mathrm{CLS}_{\mathrm{M}}$ & $C_{L} S_{L}$ & $\mathrm{CH}_{\mathrm{M}}$ & $\mathrm{CH}_{\mathrm{H}} \mathrm{S}_{\mathrm{L}}$ & Total \\
\hline Relief & Protective & 1 & 3 & 5 & 12 & 21 \\
\hline Recovery & Protective and promotive & & 1 & 2 & 5 & 8 \\
\hline Resilience & \multirow[t]{4}{*}{ Preventive and promotive } & 1 & 2 & 4 & 6 & 13 \\
\hline Resilience-agriculture and livestock & & 1 & & 2 & 3 & 6 \\
\hline Resilience-finance & & & 2 & 1 & 2 & 5 \\
\hline Resilience-diversification & & & & 2 & 1 & 3 \\
\hline Promotion & \multirow[t]{4}{*}{ Promotive } & 4 & 3 & 10 & 12 & 29 \\
\hline Promotion-labour demand & & & 1 & 2 & 4 & 7 \\
\hline Promotion-labour supply & & 4 & 1 & 6 & 5 & 16 \\
\hline Promotion-non-specific & & & 1 & 2 & 4 & 7 \\
\hline Peacebuilding & Transformative & & & 2 & 4 & 6 \\
\hline Total (objectives count) & & 6 & 9 & 24 & 40 & 79 \\
\hline Total (programmes) & & 4 & 7 & 12 & 19 & 42 \\
\hline
\end{tabular}

${ }^{*}$ Count in bold represents the number of programmes within a given objective. Count not in bold breaks down the category into sub-objectives. One programme can have multiple sub-objective types within one objective, so the sum of programmes for all sub-objectives can exceed the total for the relevant objective.

The total count of objectives is more than the total number of programmes $(n=42)$ because most programmes have multiple objectives. We count the number of programmes that have at least one objective linked to relief, recovery, promotion, resilience, and peacebuilding, and the sub-categories within those (if any). We will first briefly describe each of these before analysing the key differences in (and give examples of) objectives across the four implementation/context categories.

\subsubsection{Relief (or protective social protection)}

Immediately after a shock, particularly in contexts of fragility, much of the efforts are focused on relief aid to reduce people's poverty and vulnerability and ensure food security. These intend to cover basic needs (e.g., nutritional and food security), in contexts where markets are disrupted, by addressing access to and availability of food and basic services for the community. Relief-oriented cash-plus programmes approximate the 'protective' objective of social protection programmes in stable settings. Half of the programmes reviewed (21) had an objective linked to relief/protection. 


\subsubsection{Recovery (a mixture of protective and promotive social protection)}

Recovery, restoration of assets and of infrastructure, is particularly relevant in conflict-affected settings as it emerges from the need to repair infrastructure and access to basic services that were lost or damaged during periods of more intense violence. Underlying assumptions about the impact of these recovery programmes concern their potential to enable community restorations and rehabilitation, but also to increase social cohesion (linked to the 'peace-building' objective, see below). These interventions are often seen as a way to address collective needs as opposed to individual or household-level ones. Recovery initiatives do not have a direct parallel in stable settings, as they are obviously very specific to rebuilding and re-establishing after damage and asset depletion has occurred. They serve both protective and promotive functions. In total, only eight of the programmes reviewed had objectives linked to livelihood recovery.

\subsubsection{Resilience (a mixture of preventive and promotive social protection)}

In contexts of fragility, some programmes aim to increase resilience ${ }^{7}$ through seeking to avert deprivation, and they often do this at the individual or household levels. Out of 14 sub-objectives identified throughout 13 programmes linked to resilience, 6 focus on using agriculture and livestock as a basis for creating resilience, a further 5 aim to leverage financial services availability and access for resilience, and 3 do so by promoting diversification of income-generating activities. Resilience-based programmes approximate both preventive and promotive objectives of social protection programmes in stable settings.

On closer inspection, although 23 programmes across the whole sample use 'resilience' terminology to describe their objectives, such as graduation, cash-plus, resilience, productive inclusion, sustainable production capacity, sustainable assets, sustainable development, sustainable employment, sustainable income, sustainable livelihoods, lifting out of or breaking free from poverty (and, in some cases, to name the programmes themselves), only 11 incorporate specific sub-objectives focused on resilience and concrete actions pursued through agriculture, finance or diversification. Thus, the use of these terms in high-level programme documentation - while reflecting a desire to associate programming efforts with discourses that garner acceptability, attention, and funding- may not actually be describing how resilience-type interventions are being implemented in practice.

\subsubsection{Promotion (or promotive social protection)}

Parallel to graduation objectives that intend to boost livelihoods of poor and vulnerable people, these were the most frequent objectives among identified programmes. In programme documents, language around livelihoods promotion is often framed as a way to improve labour demand, access to labour markets, and income-generating opportunities on the one hand, and labour supply, capacities, and productivity and skills of workers (including for self-employment as per Flynn et al. 2017) on the other. It is also sometimes framed with 'improving livelihoods' statements in a non-specific, vague sense without further details of what aspect of livelihoods they are trying to enhance. These kinds of programmes are often household-focused but can also have elements that intend to strengthen certain community aspects (e.g., partner with other community members in business activities).

Out of 30 objectives (from 29 programmes) linked to livelihood promotion, 7 were primarily concerned with improving labour demand, 16 labour supply, and 7 made more non-specific statements without further details or clarifications. The language of promotion is certainly used, but more careful assessment of individual programmes, and forensic examination of the modalities, is necessary to determine what proportion of these are truly promotive.

\subsubsection{Peacebuilding (or transformative social protection)}

So far, apart from the language of 'recovery', the objectives of most programmes are framed in ways that are not dissimilar to what can be observed in settings not affected by armed conflict. When trying to identify what is different about contexts experiencing conflict-related violence, there are some programmes that have objectives linked to fragility, particularly around governance, social cohesion, preventing conflict, reducing the risk of violence, and/or peacebuilding. These interventions are geared to the community level reflecting the intention to influence social relationships. Programmes that intend to encourage social cohesion through boosting income-generating opportunities often carry an underlying assumption that employment improves

${ }^{7}$ Béné (2013: 22) defines resilience as the 'ability to persist, adapt or transform in the face of a shock or changing environment'. 
livelihoods, reducing tensions and the risks of recruitment to violent activities, thus contributing to more peaceful outcomes. While we would expect that most cash-plus programmes in conflict-affected settings would incorporate consideration of how their activities contribute (directly or indirectly) to peacebuilding, only six programmes state this as an explicit objective. It may be that the lack of more ambitious programming aims simply reflects that it is not possible (e.g., that agencies lack the capacities, knowledge, and connections with stakeholders to demonstrate influence and impact in the wider social and political dynamics underpinning peace-building processes). Moreover, some operational agencies may consider that incorporating peace-building objectives is inappropriate given levels of need and, thus, maintain a rightful focus on protective, preventive, and promotive aims. The lack of programmes with a transformative focus might also imply that there is inadequate understanding of how discrete programmes, often implemented by outside agencies, can be effective in this space considering the broader political economy of conflict, and the role of aid within this.

\subsubsection{Analysis of programming objectives in different implementation settings}

In this section we describe the objectives of programmes in the different conflict-social protection implementation contexts. Most of the programmes have multiple objectives. These findings should be treated with some caution given that the number of programmes and objectives in some categories is very low. Across all country categories, relief and promotion objectives are the most common ones. Recovery and peacebuilding, both not expected to be relevant in stable contexts, are minor in our sample and do not come up at all in low conflict/moderate social protection system strength (and no peace-building objectives either in low conflict/low social protection system strength). This could be because the low conflict intensity results in minimal effects of conflict-related violence on infrastructure or social cohesion. These two objectives do appear, along with the others (relief, resilience, and promotion) at least once across the high conflict country categories. For example, in these contexts, recovery programmes aim to rehabilitate and strengthen community assets and resilience (in South Sudan, programme 33, the Famine response project, 'sought to support the rehabilitation of community infrastructure which benefits the whole community'). Furthermore, peacebuilding may aspire to address governance deficits, radicalisation, and social tensions that arise from the conflict, displacement, and post-conflict situation. It could also aim to build government skills, advocate for peace-building among participants, and prevent further post-conflict deterioration ('building the skills and capacity of... the government. To... prevent further deterioration of post-crisis situations'; programme 9, Iraq Crisis Response and Resilience Programme).

Programme objectives that aim to promote labour supply are particularly frequent in settings of moderate social protection system strength. For instance, this is framed as building the skills and capacity of workers, or through enhancing investments in self-employment by investing in productive activities or increasing production capacity and productivity of self-employed farmers ('to strengthen the capabilities and competencies for income generation of the members of families belonging to the Unidos Network', programme 3, Social Prosperity Income Programme, Colombia). This is the case for all four programmes in low conflict intensity settings and half of the programmes in high conflict settings. In both these categories, where social assistance systems function but are unable to respond to repeated crises, it could be that programmes simply revert to the standard focus on short-term enhancement of labour supply. Furthermore, this could illustrate a limited adaptation of the design and implementation of context-specific programmes. This is not an issue in Jordan, which is a peaceful country, but more likely in Colombia, where the link with conflict legacies seems more relevant. Relief objectives are more common in contexts of high conflict intensity and low social protection system strength, mainly to meet basic needs and protect the most vulnerable people. In these contexts, programmes aim to avert the intensified deprivation and destruction resulting from the conflict through assistance that covers household needs, access to basic services, food security, and nutrition ('Increase the access to and availability of diversified and nutritious food for households in the region'; programme 29, Emergency Food Security Programme using Mobile Money, Somalia). 


\subsection{Modalities $^{8}$}

Many of the components in the identified programmes are similar to those found in stable settings, yet in stable settings hard conditionalities are more common, related to children's education (enrolment and completing certain levels), health (child immunisation and other screenings), and nutrition. We would not expect to see hard conditions deployed in high conflict or fragile settings as the infrastructure is likely to be inadequate to allow the participants to successfully meet the conditions. For instance, if schools have been damaged or children are unable to go to school for reasons of safety, then there is little point in imposing a condition. Similarly, there is no point insisting on health conditions if people cannot travel safely to the clinic and/or if there are no medical personnel present. This, coupled with the small available evidence base of their success in crises settings, often results in many implementing agencies avoiding hard conditionalities. There are other conditions that might link more directly to livelihood outcomes that would not pose as much of a barrier for beneficiaries in conflict-affected settings, such as work (through public works) or developing a business proposal. Furthermore, it might be helpful to impose soft conditions (or options) in some of these contexts - such as training and sensitisation campaigns, financial literacy, and savings (if financial institutions are available), and rotating savings groups. Public works/cash-for-work imply a work requirement, useful for relief and recovery, and community asset promotion. If it is safe to go to work and the programme is designed well, this requirement in FCAS could serve multiple purposes. Because some of the challenges (conflict, undermined institutions) in delivering social assistance and its 'plus' components are greater in these contexts, programmes often tend to highlight the benefits of less frequent transfers in order to reduce risks during distribution and to minimise costs. Programme duration (tied to funding) is, on average, 4.8 years; however, people receive support for a fraction of this time. ${ }^{9}$

\subsubsection{Cash component}

The methodology used for this study ensured that all programmes include a cash transfer component. In 32 programmes, this was provided as a regular/frequent payment, and in 18 it was provided as a one-off lump sum payment. These lump-sum payments could be in the form of an individual business start-up grant at the start or end of a programme. Eight programmes combined these modalities, meaning that some of the cash component was provided in a lump sum (e.g., start-up grant) and some other cash component was provided with certain frequency (e.g., cash-for-work). Transfers were delivered as a multipurpose transfer either through mobile methods or a commercial bank account to promote recipients' access to financial services. A total of 20 programmes lasted less than 4 years, 14 lasted between 4 and 7 years, and only 8 programmes lasted 7 or more years, with beneficiaries often participating in them for only a fraction of that time.

The majority of transfer elements of programmes were provided with conditions (31 programmes) and 21 programmes either contained multiple components that combined conditional (e.g., cash-for-work) and unconditional (a grant) or were entirely unconditional. Conditionalities entailed work (e.g., cash-forwork/assets), where able-bodied people temporarily engage in hours of labour on intensive public works activities (restoring infrastructure such as roads, water, and sanitation) in exchange for low wages. Other conditions involved the performance of certain income-generating activities (including the development of business proposals) that aimed to promote sustainable employment and/or higher incomes (e.g., activities that add value to production and improve access to markets), and nudging for increased savings, training, or health behaviour. Ten programmes provided both conditional and unconditional transfers, often to different beneficiaries.

\subsection{2 'Plus' component}

In the identified programmes, cash is often accompanied by other components, of which skills training is the most common (36 programmes), teaching participants technical, vocational, life, soft, and basic business skills. Technical and business training for organisations and individuals aims to boost productive capacities and livelihoods. In particular, training focuses on climate-sensitive agriculture (to help increase food production and build longer-term resilience), climate-resilient irrigation, gardening, animal health care,

${ }^{8}$ In this paper, 'modality' refers to the form of assistance (e.g., cash, skills training, mentoring, etc.). This is different to the delivery mechanisms (how assistance is transferred: cash in envelope, digital, etc.), any conditionality the assistance might depend on (e.g., conditional on hours of work, school attendance, health check-ups, etc.) or to the frequency of the assistance provided (e.g., regular transfers, lump sums).

9 The average length of time people receive support (as opposed to the average length of programmes) could be a subject of research for BASIC Research in the future. 
business development, and financial literacy. Many of these are usually a prerequisite for receiving recovery grants or assets. Life skills training (conflict prevention, group dynamics, hygiene, HIV prevention, gender relations) and vocational training in areas where the local job market offers employment opportunities based on local market analysis are also used. Coaching, mentoring, and community sensitisation sessions (16 programmes) are also used. Coaching/ mentoring included livelihoods schemes, business planning, supervision, and advisory services. Sensitisation was often about nutrition, child feeding practices, hygiene promotion, individual aspirations, social norms, nutrition-sensitive agriculture, sanitation, water conservation, and the environment.

Other frequent components included agricultural extension services (15 programmes), which offer technical advice on agriculture to smallholder farmers, and also supply them with inputs (planting kits) and services (improved technology and practices) to support their agricultural production beyond subsistence farming. Some of the practices can save them labour and time, such as irrigation services, provision of solar pumps, and hired tractors to prepare land for planting. Extension services are also useful for providing general and specific information related to markets, agricultural and veterinary practices, and so on. Furthermore, 11 programmes provided productive asset transfers for on-farm and off-farm livelihood activities to support economic opportunities and increased incomes. These include in-kind livestock inputs (goats, animal feed, vaccination, and treatment) and starter packages (such as fishing kits and solar-powered fridges) among others.

Access to finance, including microcredit and savings, is also common (13 programmes) through the creation of groups and establishment of group-based savings mechanisms, access to savings accounts, microfinance grants, and loans. Market links and information (8 programmes) intend to help strengthen value chains. Other components involve animal health services, which were provided to reduce livestock mortality through (for example) vaccinations and training of community animal health workers (4 programmes). Also, apprenticeship placements with a stipend for those beneficiaries with some form of education (2 programmes), health care and counselling provision (4 programmes), food and nutrition aid (2 programmes), and job matching (1 programme) were provided, though less frequently.

\subsubsection{Analysis of programming modalities in different implementation settings}

CCTs are more common than UCTs across all country categories (see Table 5.2). The use of conditions (mostly associated with work, either as part of public works or self-employment) is more likely in settings where there are high levels of conflict and where the social protection system is of moderate strength. In these contexts, where infrastructure might have been damaged due to the conflict and fragility, an existent social protection system provides cash in exchange for work conditions (10 out of 12 programmes in this category provide CCTs, seven of those in exchange for work, such as programme 23 from north-east Nigeria, Inclusive Basic Service Delivery and Livelihood Empowerment Integrated Programme (IBSDLEIP), which, among other components, consists of public works for improved infrastructure and facilities for basic service delivery in health, education, water, and sanitation).

Also, there are no apparent patterns when looking at the type of conditionalities imposed. For example, workbased conditionalities are most apparent in low conflict/moderate social protection systems and high conflict/weak social protection systems - opposite ends of the spectrum. Business-based conditionalities are also more likely at opposite ends of the spectrum (low conflict with low social protection system strength and high conflict with moderate social protection system strength). For instance, programme 8 from Iraq, IQYouth Livelihoods Development in Southern Iraq, awards a small grant to selected youth microenterprise start-up proposals. Apart from 'health', these are not the standard types of conditions that come up in a stable setting. They are majorly soft conditions, and very few conditions require the participant to fulfil an additional criterion such as education or nutrition checks.

Regarding the 'plus' components, skills training is the most common modality across all settings, except contexts with low conflict intensity and moderate system strength (where it is equally common along with access to finance, coaching, mentoring, and sensitisation, and market links and information). Agricultural extension and asset transfers are somewhat more likely to be used in high conflict settings (such as with programme 41 in Yemen, Smallholder Agricultural Production Restoration and Enhancement Project, whereas coaching, mentoring, and sensitisation are more likely in lower conflict settings (e.g., programme 18 in Niger, ASP productive inclusion programme). While we have discussed that some of the above objectives 
are to do with FCAS (peacebuilding and recovery), apart from the infrequent life skills training for conflict prevention (for example, in programme 32, Building Resilience through Asset Creation and Enhancement (BRACE) II, in South Sudan), there is nothing obvious in the plus modalities that equate with that. Overall, there is a mismatch between programme objectives and the plus component.

Small-scale programmes are most apparent in settings with low conflict intensity, whereas settings with high conflict intensity have more programmes with larger coverage.

Table 5.2: Count of social assistance and protection/protecting component type by country category

\begin{tabular}{|c|c|c|c|c|c|}
\hline Values & $\mathrm{C}_{\mathrm{L}} \mathrm{S}_{\mathrm{M}}$ & $C_{L} S_{L}$ & $\mathrm{C}_{\mathrm{H}} \mathrm{S}_{\mathrm{M}}$ & $\mathrm{C}_{\mathrm{H}} \mathrm{S}_{\mathrm{L}}$ & Total \\
\hline \multicolumn{6}{|l|}{ SOCIAL ASSISTANCE (cash component) } \\
\hline Unconditional & 2 & 4 & 4 & 11 & 21 \\
\hline Conditional (work) & 3 & 3 & 7 & 12 & 25 \\
\hline Conditional (savings) & & 1 & 1 & & 2 \\
\hline Conditional (health) & & & & 1 & 1 \\
\hline Conditional (business) & & 2 & 4 & 2 & 8 \\
\hline \multicolumn{6}{|c|}{ SOCIAL PROTECTION/PROTECTING (plus component) } \\
\hline Skills training & 3 & 7 & 11 & 15 & 36 \\
\hline Coaching, mentoring, and sensitisation & 3 & 4 & 3 & 6 & 16 \\
\hline Agricultural extension & & 1 & 7 & 7 & 15 \\
\hline Access to finance & 3 & 2 & 3 & 5 & 13 \\
\hline Asset transfer & & 1 & 3 & 7 & 11 \\
\hline Market links and information & 3 & 1 & 2 & 2 & 8 \\
\hline Others* & 0 & 3 & 5 & 6 & 14 \\
\hline Total (count of programmes per category) & 4 & 7 & 12 & 19 & 42 \\
\hline
\end{tabular}

${ }^{*}$ Others include animal health services; health care and counselling; apprenticeships and education; food and nutrition provision; job matching - each with under five observations in aggregate.

\subsection{Targeting criteria}

Many of the programme documents provided information around eligibility criteria but lacked clarity on targeting mechanisms or tools used to identify those beneficiaries. Therefore, for the analysis of targeting, we will focus on targeting criteria (instead of targeting mechanisms and tools). In many of these contexts and programmes, targeting aims to consider the drivers of fragility (see details in Table 5.3). This is frequently done through the use of categorical targeting, by using proxies for categories of: people thought to be at risk of recruitment by armed groups or intensifying fragility/conflict (i.e. young people - 18 programmes); people that are at risk of deprivation as they have been forcibly displaced (i.e. forcibly displaced - 16 programmes, with 10 programmes that directly target IDPs and 10 that target refugees); and poor/vulnerable people that host the displaced (i.e. conflict-affected - 16 programmes). Both forcibly displaced and conflict-affected populations are more likely to be part of the eligibility criteria in programmes in contexts of low conflict intensity and moderate social protection system strength (e.g., programme 10, Project Match in Jordan, which targeted Syrian refugees and host Jordanian communities). It is in this category where all the identified programmes targeted at least one of the groups of concern. It is in settings of nascent social protection systems that it is more likely that programmes overlook populations of concern as explicitly targeted, and instead target other groups (just under half of the programmes in both country categories). For instance, programme 2, Targeting the Ultra-Poor (TUP) graduation programme, targets ultra-poor households in six 
provinces of Afghanistan. Considering these categories (or 'fragility-specific target group', FSTG) as the eligible groups in the targeting process of social assistance in fragile settings, implies a design flowing from a programme objective (explicit or implicit) to prevent and reduce violence and tension. However, not all the programmes have a FSTG, and instead address other categories of eligibility criteria (16 programmes).

Table 5.3: Programme eligibility criteria used, by country category

\begin{tabular}{|c|c|c|c|c|c|}
\hline Targeted groups & $\mathrm{CLS}_{\mathrm{M}}$ & $C_{L} S_{L}$ & $\mathrm{CH}_{\mathrm{M}}$ & $\mathrm{CH}_{\mathrm{H}} \mathrm{S}_{\mathrm{L}}$ & Total \\
\hline \multicolumn{6}{|l|}{ Fragility-specific target group (FSTG) } \\
\hline Count of programmes with at least one FSTG & 4 & 4 & 8 & 10 & 26 \\
\hline Youth & 2 & 2 & 6 & 8 & 18 \\
\hline Conflict-affected & 3 & 2 & 4 & 7 & 16 \\
\hline Forcibly displaced & 3 & 3 & 4 & 6 & 16 \\
\hline IDPs & 1 & & 3 & 6 & 10 \\
\hline Refugees & 3 & 3 & 2 & 2 & 10 \\
\hline \multicolumn{6}{|l|}{ Other population targeted } \\
\hline Count of programmes with other vulnerable target groups & 3 & 4 & 11 & 17 & 35 \\
\hline Women & 2 & 3 & 7 & 11 & 23 \\
\hline Geography (poor, vulnerable, insecurity) & 1 & 2 & 6 & 9 & 18 \\
\hline Poor & 2 & 3 & 5 & 7 & 17 \\
\hline Vulnerable (food insecure) & & 1 & 2 & 6 & 9 \\
\hline Unemployed/underemployed & 1 & & 3 & 3 & 7 \\
\hline Disabled & 1 & & 1 & 3 & 5 \\
\hline Farmers/pastoralists & 1 & 1 & 2 & 1 & 5 \\
\hline Children & & & & 3 & 3 \\
\hline Elderly & & & & 3 & 3 \\
\hline Low education attainment & 1 & & 1 & & 2 \\
\hline Transgender & & & 1 & & 1 \\
\hline Total (count of all programmes) & 4 & 7 & 12 & 19 & 42 \\
\hline
\end{tabular}

Indeed, beyond the 'FSTG', women were widely targeted across country groupings, more likely in high intensity conflict settings (over half of the programmes targeted women specifically, in both country categories). This was the case of programme 16, Productive transfers (cash-plus), in Mali, in which women, and in particular women head of households, were the main recipients of programme inputs. Targeting populations in geographically vulnerable areas due to insecurity was also more common (approximately half of the programmes) in contexts of high conflict intensity. The explicit targeting of poor people was frequent across categories but especially in contexts of low conflict and moderate social protection system strength, where tools exist and are feasible to use in order to identify and determine the lowest-income households.

Programme 11 (Small Ruminant Investments and Graduating Households in Transition, SIGHT) targeted poor and extremely poor people among other groups. Less frequently targeted groups - observed in less than ten programmes each across the whole sample - were more common overall in contexts of high conflict 
intensity and moderate social protection system strength (in three-quarters of the programmes of this category). This included: vulnerable groups (e.g., to food insecurity) (two programmes in this country category); unemployed/underemployed (three programmes); people with disabilities (one programme); farmers/pastoralists (two programmes); transgender people (one programme); groups with low levels of education (one programme). Children and the elderly were not specifically targeted in this country category.

\subsection{Implementers}

Governments (17 programmes) and international NGOs (18 programmes) are the most common type of implementer across country categories. Government ministries and departments are by far the most frequent implementers in low conflict/moderate strength social protection system settings (Jordan and Colombia, 3 programmes), which reflects the more developed social protection systems in these countries. However, in settings with higher intensity of conflict and low system strength, international NGOs (9 programmes) and external funding and implementation agencies are more likely to be involved in programme delivery ('Funders', 9 programmes - including United Nations (UN) agencies such as the Food and Agriculture Organization of the United Nations (FAO), the United Nations Relief and Works Agency for Palestine Refugees in the Near East (UNRWA), the United Nations Development Programme (UNDP), the World Food Programme (WFP), and the United Nations Children's Fund (UNICEF)). This is the case for programme 32, Building Resilience through Asset Creation and Enhancement (BRACE) II, in South Sudan, which is delivered by WFP and FAO (component 1) and World Vision (component 2). Across all contexts, international rather than national NGOs are more involved in implementation. However, in contexts of low social protection system strength, national actors (government and national NGOs) are less likely to be involved than in settings with moderate strength social protection systems - which is to be expected. The private sector is a minor actor, and only in high intensity conflict settings (programmes 6 and 16, in Ethiopia and Mali respectively), as it may provide alternative means to distribute assistance.

\subsection{Impacts and outcomes}

For this paper, we collated all evaluations and assessment documents that were found in the public domain for the identified programmes using keywords that included the corresponding programme names (in addition to 'evaluation', 'assessment', and 'findings'). We also contacted implementing agencies and organisations to request evaluations for programmes for the cases we were unable to find in the public domain. Many of the programmes are still ongoing, or were delayed due to various reasons, and thus assessments have not been conducted. At this stage, we have been able to obtain the evaluation documents for 25 of the 42 programmes.

Here, we limit discussion of impacts and outcomes to a preliminary analysis of programmes for which we obtained evaluations. Specifically, we consider the indicators that were used and measured for defining 'success' and the types of methods that were used. ${ }^{10}$ Evaluation of the impacts and outcomes of programmes is patchy and usually focused on immediate/short-term impacts. Some programmes refer to the number of community assets that were constructed, with vague reference to impacts for other, more specific indicators. In general, the impacts and outcomes of these programmes are poorly documented, with many assessments based on the views of the implementing agencies (thus raising the issue of evaluation bias). Only three programmes evaluated cost-effectiveness (programmes 2, 18, and 34 from Afghanistan, Niger, and South Sudan respectively). Most evaluations assessed outcomes at endline or shortly after the end of the programme (usually within two years). Where the evaluation methods used were described, 16 used mixed methods (most assessments from programmes in countries with moderate strength social protection systems used mixed methods) (see Table 5.4). Eight based their findings on quantitative research and one did not specify its methodology (from $\mathrm{C}_{\mathrm{H}} \mathrm{S}_{\mathrm{L}}$ ). Randomised control trials (RCTs) and quasi-experiments were used in eight programmes to study the impact of different components and their interaction or to assess the effects of the programme itself or any disruption to it.

Across all 25 programme evaluations that we identified, reporting of outcomes and impacts mainly focused on income (18 programmes), social inclusion (14 programmes), and economic inclusion (15 programmes). Food security, cohesion, and wellbeing/satisfaction/expectations were also widely reported on

10 More in-depth research on the impacts and outcomes of cash-plus programmes is a proposed focus of study in the longer implementation phase of BASIC Research. 
(13 programmes each). Less frequently used indicators were animal health (1 programme), costeffectiveness ( 3 programmes), living standards (4 programmes), agricultural/livestock production (5 programmes), and protection (5 programmes).

Overall, programme impacts and outcomes across these indicators were determined to be positive. These include positive effects on incomes across all country categories (apart from two programmes that reported no changes). This was particularly the case for programmes in the $\mathrm{C}_{L} \mathrm{~S}_{\mathrm{M}}$ category, where, according to their assessments, all of the programmes resulted in increased incomes. Similarly, all assessments that reported on economic inclusion (including market access and savings, for example) highlighted positive results. Social inclusion indicators (including, for instance, gender empowerment and social capital) were generally positive apart from countries in the $C_{L} S_{M}$ category, where there is evidence of social capital reduction. With regards to social cohesion (including government support and reduced political violence, for example), only countries with high intensity conflict report on this, and approximately half of the assessments highlight a positive outcome. Food security is also evaluated in half of the evaluations of every category apart from $\mathrm{C}_{\llcorner} \mathrm{S}_{\mathrm{M}}$, with similarly positive results. Impacts on wellbeing, satisfaction, and expectations are positive, particularly in the $\mathrm{C}_{\mathrm{H}} \mathrm{S}_{\mathrm{M}}$ country category. Interestingly, the outcomes on the use of negative coping strategies are mixed. Furthermore, when it comes to work behaviours (including hours worked, use of new practices/skills), settings with low intensity conflict report no changes, but where there is a higher level of conflict, the outcomes improve.

\section{Table 5.4: Evaluation methods, by country categories}

\begin{tabular}{|l|l|l|l|l|l|l|l|}
\hline Assessments & $\mathrm{CLS}_{\mathrm{M}}$ & $\mathrm{C}_{\mathrm{L}} \mathrm{S}_{\mathrm{L}}$ & $\mathrm{C}_{\mathrm{H}} \mathrm{S}_{\mathrm{M}}$ & $\mathrm{C}_{\mathrm{H}} \mathrm{S}_{\mathrm{L}}$ & Total \\
\hline Programmes with evaluation identified & 2 & 4 & 5 & 14 & 25 \\
\hline Methods & 2 & 1 & 4 & 9 & 16 \\
\hline Mixed methods & & 3 & 1 & 4 & 8 \\
\hline Quantitative & & & & 1 & 1 \\
\hline Unknown & 1 & 3 & & 4 & 8 \\
\hline Quasi-experiment/randomised control trial (RCT) & 1 & & & \\
\hline
\end{tabular}

\section{Discussion}

A vision for resilience and long-term sustainability is required that will help conflict- and crisis-affected populations to secure their livelihoods. Efforts to strengthen livelihoods and wellbeing in conjunction with social assistance span a range of interventions, including: information and early warning systems; indexbased insurance; safety nets; supporting agricultural and livestock value chains; encouraging efforts to facilitate dialogue and peacebuilding through complementary governance programming and political processes; and using climate-smart agricultural practices. Yet, interventions in situations of protracted and recurrent crisis have at best had mixed results. In part this is because, in settings characterised by conflict and weak governance, interventions are often politicised, with those in power being able to co-opt implementation for their own interests or the interests of the group to which they belong (Crost, Felter and Johnston 2014). Aside from these fundamental concerns, there is also limited rigorous knowledge about which approaches are most effective and why.

From a comprehensive literature search on social and humanitarian cash assistance augmented by livelihood support programmes in FCAS, we identity just 42 programmes, unevenly spread across 17 countries. The vast majority of these are small in scale, especially in areas of lower intensity conflict, whereas programmes with larger coverage are apparent in some contexts of higher intensity conflict - indicating that the risk of conflict-related violence need not impede social assistance and livelihoods programming. The 
diversity in the objectives, coverage, duration, 'plus' components, and impacts is striking - indicating that there are few dominant patterns and there is significant variation. This reflects the very different landscapes of conflict and systems of social assistance provisioning that exist across the countries included in this review. This is also a reflection of the limited available evidence of what works, as well as models and guidance for cash-plus programming in conflict-affected settings. Still, some features stand out.

Regarding objectives, promotion is the most commonplace objective of cash-plus programmes, as it is in stable settings, but relief (or protective) objectives are a close second, particularly in areas experiencing higher levels of conflict-related violence. Strikingly, relatively few of the programmes reviewed incorporate objectives around resilience or peacebuilding. Less than a quarter of programmes overall in areas of high conflict intensity refer to peace-building objectives.

Regarding components, most programmes combine design features of programmes seen in more peaceful contexts - skills (training, mentoring, and coaching) being the most common component, followed by agricultural and livestock extension services, and access to finance. This is not surprising; however, what is unknown and unspecified in programme documentation is how these delivery components are adapted to conditions of conflict and fragility. Further research could illuminate the mixes of public authority that are most capable of delivery. Our review found that government agencies and sub-national public administration are by far the most common implementers in settings categorised as having moderate strength social protection systems. Yet in areas with higher levels of conflict, NGOs - and international NGOs in particular - are far more likely to be implementers. Furthermore, an international NGO may be an implementer in name only, with the real delivery happening through a constellation of locally trusted actors (including local government officials). Likewise, delivery through government structures might, in practice, happen through local customary leaders, not through lower-level political administration.

It is noteworthy that evaluation of social assistance livelihoods programmes is very patchy and mostly focused on immediate and short-term impacts. Our review found no evaluations for half of the programmes identified. We were also not able to find any impact evaluations that had been conducted some years after programme implementation. Thus, assessments of the performance of these programmes mostly rely on the statements of implementing agencies as well as the donors that fund them. Rigorous and impartial evidence is missing.

The model we presented in this paper implies that different combinations of cash-plus components might be best suited to certain contexts defined by the intensity of conflict experienced as well as the strength (or maturity) of the existing social protection system. In situations experiencing intense conflict and where delivery infrastructure for state-led social assistance is absent or severely weakened, then the obvious plus components should be primarily relief-based. Even while the primary interest is to identify how cash-plus models can be adapted in situations of crisis and which components are most effective at strengthening livelihoods, these should happen alongside and contribute to a greater objective of peacebuilding, as a key contributor to structural transformation in these settings. Further research could examine the contribution of social assistance livelihoods programming to peacebuilding specifically, and the extent to which peacebuilding should be programmed as part of livelihoods packages or whether it makes more sense for livelihoods programmes to sit apart from (but still adjacent to) wider efforts to build peace and address violence. Where conflict is low intensity, but state infrastructure (physical and social) has been destroyed, then recovery alongside relief efforts will dominate. Furthermore, in these places, there is greater scope to develop and test approaches in partnership with state actors and other trusted public authorities in order to lay the groundwork for systems that will themselves be durable. In settings with nascent state social protection systems (moderate strength) and where conflict-related violence does not impede either people's livelihoods or programme delivery, then resilience and promotive 'plus' components, alongside other components, become critical. Our review shows little systematic patterning or conclusions with regard to what works and what does not, for whom, and when. 


\section{Research agenda}

Protracted conflict, recurrent climate shocks, and forced displacement have massive implications for how, and whether, people can pursue sustainable and productive livelihoods, and whether they can access resources and markets, which are often adversely affected and/or depleted under such conditions. The guidance for how to design and implement cash-plus programmes in these settings is still nascent. This is likely due to (1) the fact that most cash-plus programmes have been developed in stable, peaceful contexts where social protection systems are functioning to some degree; and (2) the fact that cash-plus provision is primarily tailored for, and targeted to, households and individuals, with little attention to the broader economic and political context within which people live and work. Whether programmes are successful or not (and for whom), and whether they are even an option, depends on a wider environment, raising many key questions. Is infrastructure available? Are markets accessible? Do government structures function, or are there other public authorities with capacities to govern and facilitate the provision of services? Do security conditions permit routine livelihood activities?

These questions are especially pertinent in FCAS where the strength of the social protection system varies, and where protracted conflict, recurring climate shocks, and forced displacement are present to different degrees. A key area for further research is to identify which modifications (if any) to cash-plus programming are most likely to increase their effectiveness in FCAS. This also poses the question of whether programme adjustments and livelihood components (should) vary according to the type of context (strength of the social protection system, level of conflict, vulnerability to recurrent climate shocks, levels of forced displacement).

This paper demonstrates the need to further develop analytical tools to examine the delivery and effectiveness of cash-plus programmes in FCAS, as well as expanding the evidence base on the effectiveness of existing programmes and learning from implementation experiences in these places. Doing so is essential to provide some policy and programming options for designing and implementing cash-plus programmes in contexts of crisis. Further research could extend the proposed framework to incorporate different indicators of crisis and fragility, to deepen the assessment of programme outcomes and impacts, and to introduce a grounded understanding of the issues by conducting research on specific cash-plus programmes.

By assessing the outcomes of cash-plus programmes in a number of crisis settings, the research will generate actionable insights in terms of identifying which approaches have the greatest impact, and what are the key enablers and constraints on programme effectiveness in FCAS. This should generate recommendations for how to move beyond limited-scale pilots to interventions that can be programmed at a wider scale and implemented by a range of public authorities. 


\section{References}

Adato, M. and Hoddinott, J. (2007) Conditional Cash Transfer Programs: A 'Magic Bullet' for Reducing Poverty? Washington DC: International Food Policy Research Institute

Ahmad, A. (2015) 'The Security Bazaar: Business Interests and Islamist Power in Civil War Somalia', International Security 39.3: 89-117

Amnesty International (2018) Nigeria. The Harvest of Death: Three Years of Bloody Clashes Between Farmers and Herders in Nigeria, London: Amnesty International (accessed 4 January 2022)

Attah, R. et al. (2016) 'Can Social Protection Affect Psychosocial Wellbeing and Why Does This Matter? Lessons From Cash Transfers in Sub-Saharan Africa', The Journal of Development Studies 52.8: 1115-31

Baird, S.; Ferreira, F.H.; Özler, B. and Woolcock, M. (2013) 'Relative Effectiveness of Conditional and Unconditional Cash Transfers for Schooling Outcomes in Developing Countries: A Systematic Review', Campbell Systematic Reviews 9: 1-124

Bastagli, F. et al. (2016) Cash Transfers: What Does the Evidence Say? A Rigorous Review of Programme Impact and of the Role of Design and Implementation Features, London: Overseas Development Institute

Bates, R.H. (1983) Essays on the Political Economy of Rural Africa, Cambridge: Cambridge University Press

Béné, C. (2013) Towards a Quantifiable Measure of Resilience, IDS Working Paper, Vol 2013, Issue 434 (accessed 4 January 2022)

Benjaminsen, T.A. and Ba, B. (2019) 'Why Do Pastoralists in Mali Join Jihadist Groups? A Political Ecological Explanation', The Journal of Peasant Studies 46.1: 1-20, DOI:

10.1080/03066150.2018.1474457 (accessed 5 January 2022)

Carter, M.R. and Barrett, C. (2006) 'The Economics of Poverty Traps and Persistent Poverty: An AssetBased Approach', The Journal of Development Studies 42.2: 178-99

Carter, M.R. and May, J. (2001) 'One Kind of Freedom: Poverty Dynamics in Post-Apartheid South Africa', World Development 29.12: 1987-2006

Cheng, C. (2016) Post-Conflict Transitions and Extralegal Groups, Oxford: Oxford University Press Crost, B.; Felter, J. and Johnston, P. (2014) 'Aid Under Fire: Development Projects and Civil Conflict', American Economic Review 104.6: 1833-56

Davis, B. et al. (eds) (2016) From Evidence to Action: The Story of Cash Transfers and Impact Evaluation in Sub Saharan Africa, Oxford: Oxford University Press

Devereux, S. and Sabates-Wheeler, R. (2004) Transformative Social Protection, IDS Working Paper 232, Brighton: Institute of Development Studies

Dwan, K.; Gamble, C.; Williamson, P.R. and Kirkham, J. for the Reporting Bias Group (2013) 'Systematic Review of the Empirical Evidence of Study Publication Bias and Outcome Reporting Bias - An Updated Review', PLoS One 8.7: e66844. DOI: 10.1371/journal.pone.0066844 (accessed 7 January 2022)

Egger, M. et al. (1997) 'Language Bias in Randomised Controlled Trials Published in English and German', The Lancet 350.9074: 326-9

Ellis, F.; Devereux, S. and White, P. (2009) Social Protection in Africa, Cheltenham: Edward Elgar Publishing

Flynn, J.; Mader, P.; Oosterom, M. and Ripoll, S. (2017) Failing Young People? Addressing the Supplyside Bias and Individualisation in Youth Employment Programming, Youth Employment 216, Brighton: Institute of Development Studies (accessed 5 January 2022)

Gersovitz, M. and Kriger, N. (2013) 'What Is a Civil War? A Critical Review of Its Definition and (Econometric) Consequences', The World Bank Research Observer 28.2: 159-90, DOI:

10.1093/wbro/lkt005 (accessed 5 January 2022) 
Green, R. (2000) 'Rehabilitation: Strategic, Proactive, Flexible, Risky?’ Disasters 24.4: 343-62

Hashemi, S.M. and Umaira, W. (2011) New Pathways for the Poorest: The Graduation Model from $B R A C$, CSP Research Report 10, Centre for Social Protection, Brighton: Institute of Development Studies (accessed 4 January 2022)

Hidrobo, M.; Hoddinott, J.; Kumar, N. and Olivier, M. (2018) 'Social Protection, Food Security, and Asset Formation', World Development 101: 88-103

Justino, P. (2018) 'The Need to be Governed: Governance and Violence in Conflict Contexts', The Economics of Peace \& Security Journal 13.1

Konno, K. et al. (2020) 'Ignoring Non-English-Language Studies May Bias Ecological Meta-Analyses', Ecology and Evolution 10.13: 6373-84

Mansuri, G. and Rao, V. (2013) Localizing Development: Does Participation Work? Washington DC: World Bank

Maxwell, D.; Gelsdorf, K. and Santschi, M. (2012) Livelihoods, Basic Services and Social Protection in South Sudan, Secure Livelihoods Research Consortium (SLRC), Working Paper 1, London: SLRC (accessed 5 January 2022)

Maxwell, D.; Russo, L. and Alinovi, L. (2012) 'Constraints to Addressing Food Insecurity in Protracted Crises', PNAS: Proceedings of the National Academy of Sciences of the United States of America 109.31: 12321-25, DOI: 10.1073/pnas.0913215108 (accessed 5 January 2022)

Millán, T.M.; Barham, T.; Macours, K.; Maluccio, J.A. and Stampini, M. (2019) 'Long-Term Impacts of Conditional Cash Transfers: Review of the Evidence', World Bank Research Observer 34.1: 119-59

OECD (2020) States of Fragility 2020, Paris: OECD Publishing (accessed 7 January 2022)

Olson, M. (1993) 'Dictatorship, Democracy, and Development', American Political Science Review 87.3: 567-576

Roelen, K. et al. (2017) How to Make 'Cash Plus' Work: Linking Cash Transfers to Services and Sectors, Office of Research - Innocenti Working Paper No. 2017/10, Florence: UNICEF Office of Research (accessed 5 January 2022)

Sabates-Wheeler, R. (2021) 'Graduation', in E. Schüing and M. Loewe (eds), Handbook on Social Protection Systems, Cheltenham: Edward Elgar Publishing

Sabates-Wheeler, R. and Devereux, S. (2013) 'Sustainable Graduation From Social Protection Programmes', Development and Change 44.4: 911-38

Sabates-Wheeler, R.; Lind, J.; Hoddinott, J. and Tefera Taye, M. (2021) 'Graduation After 10 Years of Ethiopia's Productive Safety Net Programme: Surviving But Still Not Thriving', Development Policy Review 37.4: 511-31, DOI: 10.1111/dpr.12515 (accessed 5 January 2022)

Watson, C. and Palermo, T. (2016) Options for a 'Cash Plus' Intervention to Enhance Adolescent Wellbeing in Tanzania. An Introduction and Review of the Evidence From Different Programme Models in Eastern and Southern Africa, Florence: UNICEF Office of Research - Innocenti

Wiggins, S. et al. (2021) Livelihoods and Markets in Protracted Conflict: A Review of Evidence and Practice, London: Overseas Development Institute as part of the Supporting Pastoralism and Agriculture in Recurrent and Protracted Crises (SPARC) Consortium (accessed 5 January 2022)

Winder Rossi, N.; Spano, F.; Sabates-Wheeler, R. and Kohnstamm, S. (2017) Social Protection and Resilience: Supporting Livelihoods in Protracted Crises and in Fragile and Humanitarian Contexts, FAO Position Paper, Rome: Food and Agriculture Organization of the United Nations (accessed 4 January 2022)

Young, H. and Jacobsen, K. (2013) 'No Way Back? Adaptation and Urbanization of IDP Livelihoods in the Darfur Region of Sudan', Development and Change 44.1: 125-45

Young, H.; Osman, A.M.; Abusin, A.M.; Asher, M. and Egemi, O. (2009) Livelihoods, Power and Choice: The Vulnerability of the Northern Rizaygat, Darfur, Sudan, Medford MA: Feinstein International Center (accessed 5 January 2022) 


\section{Annexes}

\section{Annexe 1: Methods}

We acknowledge the potential biases associated with the types of literature engaged with. These include:

- Language bias: Our focus on documents published in English excludes relevant studies covering the BASIC Research countries that may be published in national languages or other 'international' languages. This limits not only the range of documents considered but may also be associated with particular Anglocentric assessments of cash-plus in crises (Egger et al. 1997; Konno et al. 2020).

- Publication bias and discoverability bias: Our focus on grey literature and academic journal articles will result in a disproportionate representation of documents available on well-indexed websites or published in international scholarly journals and by high-profile international organisations, potentially excluding studies conducted by lower-profile researchers in low- and middle-income countries. Furthermore, particularly in the case of journal publications, research with statistically significant results and positive results may be more likely to be published than research with 'non-significant' or negative findings (Dwan et al. 2013).

To mitigate these biases, we have included books and book chapters, as well as $\mathrm{PhD}$ dissertations, with the intention to expand the reach of our results to Southern and lower-profile researchers. We have also used multiple databases and websites to collate documents from geographically diverse sources.

To identify relevant literature, we conducted searches of publications (1) in electronic academic and opensource databases relevant to the fields of social assistance and livelihoods programming; and (2) by leading social assistance, livelihoods, and development research organisations (both research-focused organisations and international or regional organisations). The selection of these sources is based on our understanding of key databases and organisations relevant to the topic from prior research engagement on some of the highlighted countries as well as existing review studies to note additional relevant organisations. The list of proposed databases and organisational websites (see Table A1) has been reviewed by BASIC Research's management group. The items listed below have been selected for inclusion because overall they cover a range of disciplines relevant to the topic, are accessible via our institutional affiliations, and can provide results on grey and academic literature, book and book chapters, and PhD dissertations.

\section{Table A1: Reviewed databases and organisational websites}

\begin{tabular}{|c|c|c|}
\hline BASIC Research Zotero group library & WFP documents database & $\begin{array}{l}\text { World Bank project operations } \\
\text { database }\end{array}$ \\
\hline BASIC SPACE and TAS documents & $\begin{array}{l}\text { FAO documents database and } \\
\text { website }\end{array}$ & $\underline{\text { PEI Data Portal }}$ \\
\hline Markets in Crisis DGroups & UNDP documents database & African Development Bank Group \\
\hline $\begin{array}{l}\text { Social Protection Crisis Contexts } \\
\text { DGroups }\end{array}$ & UN database & Asian Development Bank \\
\hline University of Sussex library database & UNICEF & $\begin{array}{l}\text { Governance and Social Development } \\
\text { Resource Centre (GSDRC) }\end{array}$ \\
\hline Google Scholar & $\underline{\mathrm{IRC}}$ & Overseas Development Institute \\
\hline Google & World Vision & Socialprotection.org \\
\hline$\underline{\text { Scopus }}$ & Mercy Corps & $\underline{\text { CaLP database }}$ \\
\hline Web of Science & OECD publications database & $\begin{array}{l}\text { Secure Livelihoods Research } \\
\text { Consortium }\end{array}$ \\
\hline
\end{tabular}


Other documents were collated through direct consultation with key stakeholders with relevant experience, who were asked for references to relevant programme documents and/or associated evaluations. We used those documents to triangulate with our own selection and add additional relevant programmes.

The first step in the search involved conducting a keyword search of databases and other web-based engines, using a structured approach that allows for systematic review and replication (see Table A2). The second step included performing an initial review of keywords on titles, table of contents, abstracts/summaries, introduction, and of full papers. In the third step, programmes and their sources that met the inclusion criteria were recorded $(n=42)$ and coded according to a number of key criteria in an Excel database of social assistance and livelihood programmes in crises. In the fourth and final step, we performed a descriptive analysis and synthesis of programme design and implementation features.

\section{Table A2: Keywords for database and web searches}

\begin{tabular}{|l|l|}
\hline Topic & Search terms \\
\hline A - Social assistance & $\begin{array}{l}\text { Cash OR transfers OR grants OR CT OR CVA OR CBT OR CBP OR 'Cash-for-work' } \\
\text { OR 'public works' OR PWP }\end{array}$ \\
\hline B - Livelihoods programmes & $\begin{array}{l}\text { 'Cash plus' OR 'multipurpose cash' OR 'productive inclusion' OR 'graduation' OR } \\
\text { 'livelihoods programme' OR 'recovery programmes' 'rehabilitation programmes' OR } \\
\text { 'resilience programmes' OR 'skills training' OR 'asset transfer' OR 'access to finance' } \\
\text { OR microcredit OR 'agricultural extension' OR 'animal health' }\end{array}$ \\
\hline C - Country & $\begin{array}{l}\text { Yemen OR Somalia OR Lebanon OR Jordan OR Niger OR Mali OR Nigeria OR Iraq } \\
\text { OR DRC OR 'Democratic Republic of Congo' OR 'South Sudan' OR Ethiopia OR } \\
\text { Mozambique OR 'Central African Republic' OR Libya OR Syria OR Afghanistan OR } \\
\text { Myanmar OR Pakistan OR Haiti OR Colombia OR Venezuela OR Ukraine }\end{array}$ \\
\hline D - Key organisation & $\begin{array}{l}\text { FAO OR WFP OR UNICEF OR IRC OR 'World Vision' OR 'Mercy corps' OR 'World } \\
\text { Bank' OR OECD OR UNDP }\end{array}$ \\
\hline
\end{tabular}

These search terms were used in various configurations depending on the database used, based on the search options and limitations of each database. For databases that allow for more comprehensive Boolean strings, the search strings will include, for example, combinations of the following categories of keywords:

- Search step 1: A and B

- Search step 2: A and B and C

- Search step 3: A and B and C and D

For organisational websites where search functions are limited to basic keywords and with no focused search filters, site-focused Google searches were conducted using more complex search strings, such as site: www.odi.org A and B.

In addition to the above strategies, the reference lists and annexes of selected documents and systematic reviews were reviewed for additional sources, using a 'snowballing approach'.

We adopted three strategies to identify relevant evidence:

- First, the searches of databases and organisational websites (list above);

- Second, other relevant studies identified via database and website searches for references;

- Third, Google searches to identify additional materials using the following keywords: $A$ and $B$ and $C$ and D.

The inclusion criteria for livelihood programmes in fragile contexts was as follows:

- Document type: academic journal articles, grey literature, books and book chapters, and PhD dissertations;

- Modalities: cash transfers or public works programmes or grants, which can be accompanied by skills training, asset transfers, agricultural extension, microcredit, access to finance, and animal health services; 
- Year of publication: studies published over the past 10 years (since 2011), for programmes active at some point during the past 10 years;

- Language of publication: English;

- Countries covered: only BASIC Research countries (Yemen, Somalia, Lebanon, Jordan, Niger, Mali, Nigeria, Iraq, DRC, Congo, South Sudan, Ethiopia, Mozambique, Central African Republic, Libya, Syria, Afghanistan, Myanmar, Pakistan, Haiti, Colombia, Venezuela, Ukraine).

The original coding framework was:

- Programme name;

- Country and region;

- Start year;

- End year;

- Funding agency;

- Delivery partners;

- Social assistance modalities: transfers or public works programmes or grants;

- Social protection modalities: skills training, asset transfers, agricultural extension, microcredit, access to finance and animal health services (and any additional ones);

- Conditionality;

- Lump sum vs not;

- Scale/coverage (per household);

- Targeting criteria;

- Objective;

- Impacts/outcomes (if any);

- Evaluation methods (if any);

- Links to sources.

To address any gaps in the coding, further searches were conducted in the public domain to obtain any missing data. However, if information relevant for most of the coding elements was not found in the public domain, then the programme was excluded from the database.

Calibration was undertaken at the start of the quality assessment process, with 15 programmes assessed independently by two members of the project team. This provided the opportunity to verify inclusion criteria, the coding framework and identify any necessary changes.

The list of 42 identified programmes is set out in Table A3. 
Table A3: Identified and reviewed cash-plus programmes that met the criteria

\begin{tabular}{|c|c|c|c|c|c|}
\hline $\begin{array}{l}\text { Programme } \\
\text { number }\end{array}$ & Programme name & Country & $\begin{array}{l}\text { Country } \\
\text { category }\end{array}$ & $\begin{array}{l}\text { Start } \\
\text { year }\end{array}$ & $\begin{array}{l}\text { End } \\
\text { year }\end{array}$ \\
\hline 1 & $\begin{array}{l}\text { Introducing New Vocational Education and Skills } \\
\text { Training (INVEST) }\end{array}$ & Afghanistan & $\mathrm{CH}_{\mathrm{H}} \mathrm{S}_{\mathrm{L}}$ & Jan-11 & Jan-15 \\
\hline 2 & Targeting the Ultra-Poor (TUP) graduation programme & Afghanistan & $\mathrm{C}_{\mathrm{H}} \mathrm{S}_{\mathrm{L}}$ & Jun-16 & Jun-17 \\
\hline 3 & Social Prosperity Income Programme & Colombia & $\mathrm{CLS}_{\mathrm{M}}$ & Jan-11 & Jun-21 \\
\hline 4 & Transforming My Future & Colombia & $\mathrm{CLS}_{\mathrm{M}}$ & Feb-14 & Sep-20 \\
\hline 5 & DRC Eastern Recovery Project & DRC & $\mathrm{C}_{\mathrm{H}} \mathrm{S}_{\mathrm{L}}$ & May-14 & Jun-18 \\
\hline 6 & $\begin{array}{l}\text { Pastoralist Areas Resilience Improvement through } \\
\text { Market Expansion (PRIME) }\end{array}$ & Ethiopia & $\mathrm{CH}_{\mathrm{H}} \mathrm{S}_{\mathrm{M}}$ & Oct-12 & Sep-17 \\
\hline 7 & Chemen Lavi Miyò (CLM): from Fonkoze & Haiti & $\mathrm{C}\left\llcorner\mathrm{S}_{\mathrm{L}}\right.$ & Jan-95 & Jun-21 \\
\hline 8 & IQ-Youth Livelihoods Development in Southern Iraq & Iraq & $\mathrm{CH}_{\mathrm{H}} \mathrm{S}_{\mathrm{M}}$ & Jan-11 & May-15 \\
\hline 9 & $\begin{array}{l}\text { Iraq Crisis Response and Resilience Programme } \\
\text { (ICRRP) }\end{array}$ & Iraq & $\mathrm{C}_{\mathrm{H}} \mathrm{S}_{\mathrm{M}}$ & Oct-14 & Dec-21 \\
\hline 10 & Project Match & Jordan & $\mathrm{C}_{\llcorner} \mathrm{S}_{\mathrm{M}}$ & Feb-19 & Dec-19 \\
\hline 11 & $\begin{array}{l}\text { Small-Ruminant Investments and Graduating } \\
\text { Households in Transition (SIGHT) }\end{array}$ & Jordan & $C_{L} S_{M}$ & May-18 & Dec-23 \\
\hline 12 & Livelihoods Centres & Lebanon & $\mathrm{C}\llcorner\mathrm{S}\llcorner$ & Feb-14 & Jun-21 \\
\hline 13 & $\begin{array}{l}\text { Sustainability, income generation and job creation } \\
\text { through the support of irrigation and water collection } \\
\text { infrastructure in Lebanon (Phase IV) }\end{array}$ & Lebanon & $C_{\llcorner} S_{\llcorner}$ & Feb-21 & Mar-23 \\
\hline 14 & Syria Regional Crisis Emergency Appeal & Lebanon & $C_{\llcorner} S_{\llcorner}$ & Jan-11 & Jun-21 \\
\hline 15 & Emergency Safety Nets Project 'Jigisemejiri’ & Mali & $\mathrm{CH}_{\mathrm{H}} \mathrm{S}_{\mathrm{L}}$ & Apr-13 & Dec-22 \\
\hline 16 & Productive transfers (Cash-plus) & Mali & $\mathrm{C}_{\mathrm{H}} \mathrm{S}_{\mathrm{L}}$ & Jan-17 & Jul-18 \\
\hline 17 & Input subsidy programme & Mozambique & $\mathrm{C}\left\llcorner\mathrm{S}_{\mathrm{L}}\right.$ & Jun-09 & Dec-12 \\
\hline 18 & $\begin{array}{l}\text { Niger ASP productive inclusion programme/ } \\
\text { Projets Filets Sociaux Adaptifs (Niger) }\end{array}$ & Niger & $C_{\llcorner} S_{\llcorner}$ & Apr-17 & Oct-18 \\
\hline 19 & $\begin{array}{l}\text { Youth Employment and Productive Inclusion Project } \\
\text { (PEJIP) }\end{array}$ & Niger & $\mathrm{C}\llcorner\mathrm{S}\llcorner$ & Jun-18 & Jun-23 \\
\hline 20 & $\begin{array}{l}\text { Agro-Processing, Productivity Enhancement, and } \\
\text { Livelihood Improvement Support Project (APPEALS) }\end{array}$ & Nigeria & $\mathrm{CH}_{\mathrm{H}} \mathrm{S}_{\mathrm{M}}$ & Dec-19 & Sep-23 \\
\hline 21 & FADAMA III & Nigeria & $\mathrm{C}_{\mathrm{H}} \mathrm{S}_{\mathrm{M}}$ & Mar-09 & Dec-19 \\
\hline 22 & Feed the Future Nigeria Livelihoods Project (FtFNLP) & Nigeria & $\mathrm{CH}_{\mathrm{H}}$ & Sep-15 & Mar-17 \\
\hline 23 & $\begin{array}{l}\text { Inclusive Basic Service Delivery and Livelihood } \\
\text { Empowerment Integrated Programme (IBSDLEIP) }\end{array}$ & Nigeria & $\mathrm{CH}_{\mathrm{H}}$ & Jan-17 & Dec-21 \\
\hline 24 & Nigeria For Women Project & Nigeria & $\mathrm{CH}_{\mathrm{H}} \mathrm{S}_{\mathrm{M}}$ & Jun-18 & May-23 \\
\hline 25 & Nigeria Youth Employment and Social Support AF & Nigeria & $\mathrm{C}_{\mathrm{H}} \mathrm{S}_{\mathrm{M}}$ & Aug-16 & Jun-20 \\
\hline 26 & $\begin{array}{l}\text { Ehsaas National Poverty Graduation } \\
\text { Initiative/Programme (NPGI or NPGP) }\end{array}$ & Pakistan & $\mathrm{CH}_{\mathrm{H}}$ & Jan-17 & Jan-23 \\
\hline
\end{tabular}




\begin{tabular}{|c|c|c|c|c|c|}
\hline $\begin{array}{l}\text { Programme } \\
\text { number }\end{array}$ & Programme name & Country & $\begin{array}{l}\text { Country } \\
\text { category }\end{array}$ & $\begin{array}{l}\text { Start } \\
\text { year }\end{array}$ & $\begin{array}{l}\text { End } \\
\text { year }\end{array}$ \\
\hline 27 & $\begin{array}{l}\text { Federally Administered Tribal Areas (FATA) Rural } \\
\text { Livelihoods and Community Infrastructure Project for } \\
\text { Pakistan (RLCIP) }\end{array}$ & Pakistan & $\mathrm{CHS}_{\mathrm{M}}$ & Apr-12 & Dec-18 \\
\hline 28 & $\begin{array}{l}\text { Community Driven Livelihood and Food Security } \\
\text { Initiatives (CLFSI) }\end{array}$ & Somalia & $\mathrm{CH}_{\mathrm{H}} \mathrm{S}_{\mathrm{L}}$ & May-10 & Apr-13 \\
\hline 29 & $\begin{array}{l}\text { Emergency Food Security Program using Mobile } \\
\text { Money }\end{array}$ & Somalia & $\mathrm{CHSL}_{\mathrm{L}}$ & Oct-16 & Nov-17 \\
\hline 30 & $\begin{array}{l}\text { Sustainable Employment and Economic Development } \\
\text { in Somalia (SEED) II }\end{array}$ & Somalia & $\mathrm{C}_{\mathrm{H}} \mathrm{S}_{\mathrm{L}}$ & Dec-10 & Mar-15 \\
\hline 31 & $\begin{array}{l}\text { Wadajir - Enhancing Durable Solutions for and } \\
\text { Reintegration of Displacement Affected Communities } \\
\text { in Somaliland }\end{array}$ & Somalia & $\mathrm{C}_{\mathrm{H}} \mathrm{S}_{\mathrm{L}}$ & Mar-17 & Feb-20 \\
\hline 32 & $\begin{array}{l}\text { Building Resilience through Asset Creation and } \\
\text { Enhancement (BRACE) II }\end{array}$ & South Sudan & $\mathrm{C}_{\mathrm{H}} \mathrm{S}_{\mathrm{L}}$ & Sep-15 & Sep-23 \\
\hline 33 & Famine response project & South Sudan & $\mathrm{CH}_{\mathrm{H}} \mathrm{S}_{\mathrm{L}}$ & Oct-17 & Dec-17 \\
\hline 34 & Safety Net and Skills Development Project (SNSDP) & South Sudan & $\mathrm{CH}_{\mathrm{H}} \mathrm{S}_{\mathrm{L}}$ & Jun-13 & Feb-19 \\
\hline 35 & Targeting the Ultra Poor pilot & South Sudan & $\mathrm{CHSS}_{\mathrm{L}}$ & Apr-13 & Dec-14 \\
\hline 36 & Youth Business Start-Up Grant Program & South Sudan & $\mathrm{C}_{H} \mathrm{~S}_{\mathrm{L}}$ & Dec-14 & Dec-16 \\
\hline 37 & Urban agriculture project in Bourj Hammoud & Syria & $\mathrm{CH}_{\mathrm{H}} \mathrm{S}_{\mathrm{M}}$ & Jan-15 & Jan-16 \\
\hline 38 & Emergency Livelihoods Response Plan & Yemen & $\mathrm{C}_{\mathrm{H}} \mathrm{S}_{\mathrm{L}}$ & Jan-18 & Dec-18 \\
\hline 39 & $\begin{array}{l}\text { Enhanced Rural Resilience in Yemen Programme } \\
\text { (ERRY) }\end{array}$ & Yemen & $\mathrm{C}_{\mathrm{H}} \mathrm{S}_{\mathrm{L}}$ & Mar-16 & Dec-20 \\
\hline 40 & Multi-Purpose Cash (MPC) project & Yemen & $\mathrm{C}_{\mathrm{H}} \mathrm{S}_{\mathrm{L}}$ & Oct-17 & Apr-19 \\
\hline 41 & $\begin{array}{l}\text { Smallholder Agricultural Production Restoration and } \\
\text { Enhancement Project (SAPREP) }\end{array}$ & Yemen & $\mathrm{C}_{\mathrm{H}} \mathrm{S}_{\mathrm{L}}$ & Jul-17 & Aug-20 \\
\hline 42 & Yemen Social Protection Programme (YeSP) & Yemen & $\mathrm{C}_{\mathrm{H}} \mathrm{S}_{\mathrm{L}}$ & Sep-18 & Sep-21 \\
\hline
\end{tabular}




\section{Acknowledgements and Disclaimer}

This document was developed by the Better Assistance in Crises (BASIC) Research programme. BASIC is implemented by the Institute of Development Studies (IDS), the University of Sussex and the Centre for International Development and Training, funded by UKAid from the UK government. The views expressed in this document are entirely those of the authors and do not necessarily represent views or policies of the UK governments official policies.

The authors would like to thank Stephen Devereux, Andy Catley, Barri Shorey, and FCDO reviewers for commenting on earlier versions of this paper.

(C) IDS copyright 2022. Copyright in the typographical arrangement and design rests with IDS.

This publication (excluding the logos) may be reproduced free of charge in any format or medium, provided that it is reproduced accurately and not used in a misleading context. The material must be acknowledged as IDS copyright with the title and source of the publication specified.

Published by IDS.

\section{Suggested citation}

Lind, J.; Sabates-Wheeler, R. and Szyp, C. (2022) Cash and Livelihoods in Contexts of Conflict and Fragility: Implications for Social Assistance Programming, BASIC Research Working Paper 8, Brighton: Institute of Development Studies, DOI: 10.19088/BASIC.2022.008 